\title{
Hearing Loss and Cochlear Pathology in the Monkey (Macaca) Following Exposure to High Levels of Noise*
}

\author{
David B. Moody, William C. Stebbins, Joseph E. Hawkins, Jr., \\ and Lars-Göran Johnsson \\ Kresge Hearing Research Institute, University of Michigan Medical School, \\ Ann Arbor, Michigan 48109, USA
}

\begin{abstract}
Summary. Eight Old World monkeys were exposed $8 \mathrm{~h}$ daily for 20 days to octave-band noise having center frequencies from $0.5-8 \mathrm{kHz}$ at levels of 117-120 dB SPL. Two additional animals received exposures to wide-band, 120-dB SPL noise on the same schedule, and one animal was exposed to the 2$\mathrm{kHz}$ octave band for $40 \mathrm{~h}$ continuously. Behavioral audiograms were measured throughout exposure and during a 1-month recovery period. Following recovery, the animals were sacrificed and their ears examined histologically. Monaural audiograms are presented showing initial and final TTS and PTS measured at the end of the recovery period. These are compared with complete cytocochleograms for each ear. Hair cell loss was generally restricted to the outer rows, and was reasonably well correlated with pattern of hearing loss. Some cell loss, including inner hair cells, was found in the extreme basal turn, usually without associated high-frequency hearing loss. The relationships between exposure frequency, hearing loss, and locus of cochlear pathology are discussed, as are changes in TTS during exposure.
\end{abstract}

Key words: Noise-induced hearing loss - Acoustic trauma - Monkeys - TTS - PTS - Octave-band noise.

Studies of noise-related hearing loss have been characterized by two distinct approaches: epidemiological surveys of workers in noisy factories, and laboratory studies on man and animals. The surveys have provided statistical data as a basis for predictions (damage-risk criteria) of noise levels and durations of exposure which can lead to permanent hearing impairment in man. These surveys and the damagerisk criteria derived from them are reviewed by Ward (1976). The major deficiencies of such an approach for understanding how noise affects hearing include the lack of control over the conditions of exposure, both on- and off-the-job; the difficulty of

Offprint request to: David B. Moody, Ph.D. (address see above)

* This investigation was supported by research grants NS-05077, NS-05065 and NS-12706 and by Program Project grant NS-05785 from the National Institutes of Health 
excluding hearing losses caused by aging and ototoxic drugs (antibiotics, diuretics, salicylates, etc.); and the absence of inner ear histopathological data obtained within a reasonable time after exposure.

In the laboratory, more rigorous experimental studies have been carried out on man and experimental animals. Such studies in man are limited to low-level, shortduration exposures which are unlikely to result in permanent impairment. Given these constraints, it is difficult to draw conclusions from human experimentation about the conditions which lead to permanent hearing loss. In experimental animals, careful control of the total environment is possible, such that the confounding effects of other noise sources or of agents which might potentiate noise effects can be avoided. This control also extends to more accurate specification of the exact noise conditions to which an animal has been exposed.

Of course, the important issue of extrapolation from animals to man must be considered. To date, animal studies have had little influence upon the specification of damage-risk criteria. One reason that such influence has been restricted is the lack of adequate demonstration that a particular animal model yields data which are quantitatively similar to those obtained from humans. It must be recognized, however, that laboratory studies with animals are generally not designed to duplicate exactly the types of data gained by sampling industrial populations. Such sampling studies deal with large numbers of people who spend a working lifetime in a variety of noisy situations. Laboratory studies cannot deal with time spans of that length, nor can they afford to employ the large numbers of subjects required to satisfy the statistical nature of noise standards. They can, however, offer precisely controlled exposures and subsequent assessment of the extent of the damage in the inner ear. Thus, they have the potential of enabling us to specify more precisely the effects of noise on the auditory system.

A reasonable approach to laboratory studies of hearing loss is to choose an animal model that is close to man in an evolutionary sense - the monkey - and to assume that such a model will yield hearing losses in response to noise which are quantitatively similar to those observed in man. Whether this assumption is correct cannot be determined from the available data, and in fact such considerations are probably not appropriate, given our present lack of knowledge of the exact effects of noise on the ear. We believe, therefore, that a more appropriate line of inquiry for laboratory studies of noise effects should be directed towards the specification of the changes which occur in the auditory system when a hearing loss is produced by a given noise. Such studies must, as a critical first step, accurately specify the hearing loss which has occurred so that any physiological or pathological changes subsequently observed may be related to the loss.

In the present study, Old World monkeys were exposed over a 1-month period to bands of noise at levels of $117-120 \mathrm{~dB}$ SPL. One additional monkey was also exposed over a $40-h$ period. These high levels were used in order to produce substantial noise-related effects, in terms of both hearing loss and cochlear pathology. During the exposure period, and for 1 month thereafter, changes in hearing were measured with behavioral procedures employing operant conditioning techniques with positive reinforcement. At the end of the 1-month recovery period following the last exposure, the animals were sacrificed and their ears were examined for pathological changes. Of particular concern was the relationship between the frequency spectrum 
of the exposure noise, the frequencies at which hearing loss occurred, and the sites at which pathology was found in the cochlea. Also of interest was the development of threshold shifts as measured in the course of the exposure and the relationship of these shifts to the permanent threshold shifts measured 1 month after exposure was stopped.

\section{Methods}

\section{Subjects}

A total of 11 monkeys representing the Macaca nemestrina, $M$. mulatta, and $M$. fascicularis species served as subjects. They ranged in weight from $2-9 \mathrm{~kg}$ and in age from $3-9$ years. Subjects were individually housed and had free access to water. A restricted food ration was given at the conclusion of each daily testing session. The macaque species show no consistent differences in normal hearing functions and, so far as can be determined, are similarly affected by noise exposures.

\section{Apparatus}

Animals were placed in a primate restraint chair inside a double-walled sound chamber (Industrial Acoustics Co.). Their heads were restrained and they were fitted with earphones (Permoflux PDR-600 with MX-41/AR cushions) mounted on universal joints so that minor head movements did not affect the sound levels at the ear. Use of earphones made monaural testing possible so that hearing functions could be compared with individual ear histopathology. Detaills of the restraint and earphone mounting arrangements are described in Moody et al. (1970).

Mounted on the chair within reach of the monkey's tongue was a food chute through which positive reinforcers (190-mg banana-flavored food pellets, P. J. Noyes Co.) were delivered. In front of the monkey at eye level was a metal cylinder ( $44 \mathrm{~mm}$ dia by $70 \mathrm{~mm}$ long) which formed one side of a contact-sensitive circuit and served as the response device. Mounted in the center of the cylinder was a red cue light. When a monkey touched the cylinder a minute current was passed from the paw through the body to the chair, thus completing the circuit.

The experiment was controlled and data were recorded by a small computer (Digital Equipment Corp., PDP-8/L). Pure tone stimuli were produced by one of nine oscillators (HP 204C), attenuated by a programmable attenuator, and gated by a tone switch with a rise time of $50 \mathrm{~ms}$.

Earphones were calibrated both on a $6-\mathrm{cm}^{3}$ coupler and with a probe-tube microphone inserted through the cushion and placed so that the opening of the tube was directly in front of the auditory meatus when the phone was in place on the monkey.

Noise exposures were carried out in an IAC sound booth which was modified to be reverberant by lining the walls and ceiling with $3-\mathrm{mm}$ thick Masonite held in place by randomly placed $25-\mathrm{mm}^{2}$ wooden struts. The carpeting was also removed so that the floor was of solid steel plate. Two Altec "Voice-Of-The-Theater" speaker systems (511B horn, 808-8A driver, 416-8A low frequency speaker, and N501-8A crossover) were mounted near the ceiling of the room and directed at the position occupied by the monkey. The noise was produced by a General Radio 1382 noise generator, filtered by an Allison 2BR variable band-pass filter, and amplified by a McIntosh MC2105 power amplifier. Only the low frequency speaker was used to produce the $500-\mathrm{Hz}$ octave band.

The sound field spectrum was determined with a Bruel and Kjaer $1 / 2$-in. condenser microphone and a General Radio 1900-A wave analyser. Overall sound levels were measured with a General Radio 1551-C sound level meter ( $\mathrm{C}$ weighting) and/or a Bruel and Kjaer 2107 frequency analyser (flat response). The spectra of the octave bands were flat $( \pm 5 \mathrm{~dB})$ and the wide-band noise was flat $\pm 10 \mathrm{~dB}$ from $100 \mathrm{~Hz}$ to $10 \mathrm{kHz}$. 


\section{Procedure}

A cycle of the testing procedure began with the onset of a cue-light which was flashed at a rate of about $5 / \mathrm{s}$. Each animal was trained to contact the metal cylinder at this cue and to maintain contact until the tone was presented. As feedback to the animal that the response had been correctly executed, the light went from flashing to steady. When contact had been maintained for a time interval which was randomly varied from $1-9 \mathrm{~s}$, a trial was begun. On approximately $2 / 3$ of these trials, a tone was presented through one of the earphones. If the animal broke contact within $2.5 \mathrm{~s}$ after tone onset, a food pellet was delivered through the chute. Such correct detections of the tone caused the level of the tone presented on the next trial to be reduced by $10 \mathrm{~dB}$. Failure to release within $2.5 \mathrm{~s}$ of tone onset, which was counted as a miss, resulted in the tone being increased in level by $10 \mathrm{~dB}$ on the next trial. This tracking procedure was continued until the animal made ten transitions from correctly reporting the tone to missing it or vice versa. The frequency of the tone was then switched and the tracking procedure was restarted. A session continued until each ear was tested with nine different frequencies. Threshold for a given frequency was determined as the average of the last eight SPL's at which transitions occurred.

On approximately $1 / 3$ of the trials, no tone was presented. These catch trials were used to assess the rate at which the animal would "guess"; that is, release in the absence of the appropriate stimulus. Releases during these trials, or at any other time that the tone was not on, resulted in the light being turned off for $5 \mathrm{~s}$, during which the animal was required not to touch the response cylinder. Sessions in which an animal responded on more than $10 \%$ of the catch trials were not included in the data analysis. Further details of the behavioral procedure are contained in Moody et al., 1976.

Before noise exposures were begun, threshold testing was carried out until there was less than $5-\mathrm{dB}$ difference at any frequency between thresholds for 2 of the last 3 days tested. Two monkeys were assigned to each of the following exposure conditions: $500-\mathrm{Hz}$ octave band (OB), $120 \mathrm{~dB} \mathrm{SPL} ; 2-\mathrm{kHz}$ OB, $120 \mathrm{~dB}$ SPL; 4-kHz OB, $120 \mathrm{~dB}$ SPL; 8-kHz OB, $117 \mathrm{~dB}$ SPL; and wide band $(100 \mathrm{~Hz}$ to 10 $\mathrm{kHz}), 120 \mathrm{~dB}$ SPL. Each of ten animals was exposed for $8 \mathrm{~h}$ per day, 5 days per week for 4 weeks, giving $160 \mathrm{~h}$ total exposure time. The eleventh animal was exposed to the $2-\mathrm{kHz}, 120-\mathrm{dB}$ octave band for one continuous 40 -h period. No exposures were carried out on weekends. Thresholds were evaluated at all frequencies in both ears at the conclusion of each daily exposure.

Following exposure, the animals were tested daily for an additional 4 weeks to assess the amount of recovery. At the end of the 4-week recovery period the animals were sacrificed and the membranous labyrinth was stained in situ by perilymphatic perfusion of $1 \%$ osmium tetroxide solution (Zetterqvist). Whole mounts (surface preparations) of the organ of Corti and basilar membrane were examined by phase-contrast microscopy, and the percentage of hair cells remaining in each $\mathrm{mm}$ of the $25-29 \mathrm{~mm}$ length of the membrane was determined from a complete count. In counting, a decision was made whether each cell was present or absent, i.e., replaced by a phalangeal scar. No attempt was made to assess lesser degrees of damage which might be thought to signify a decreased capacity to respond to sound stimuli. Details of the histological procedures may be found in Hawkins and Johnsson (1976).

\section{Results}

Three sets of behavioral data are presented in the following figures. Threshold shifts were all plotted relative to a pre-exposure baseline defined as the median threshold at each frequency for the last 5 days before exposure. The functions labeled initial TTS were derived from the thresholds measured within $1 \mathrm{~h}$ following the conclusion of the first 8-h exposure. In general, very little recovery was noted during the testing session. The final TTS functions represent the shifts measured following the last exposure, i.e., on the 20th exposure day. The PTS functions represent the median shift determined over the last three sessions in which a given frequency was tested. Also included on most of the following figures are the cytocochleograms. 


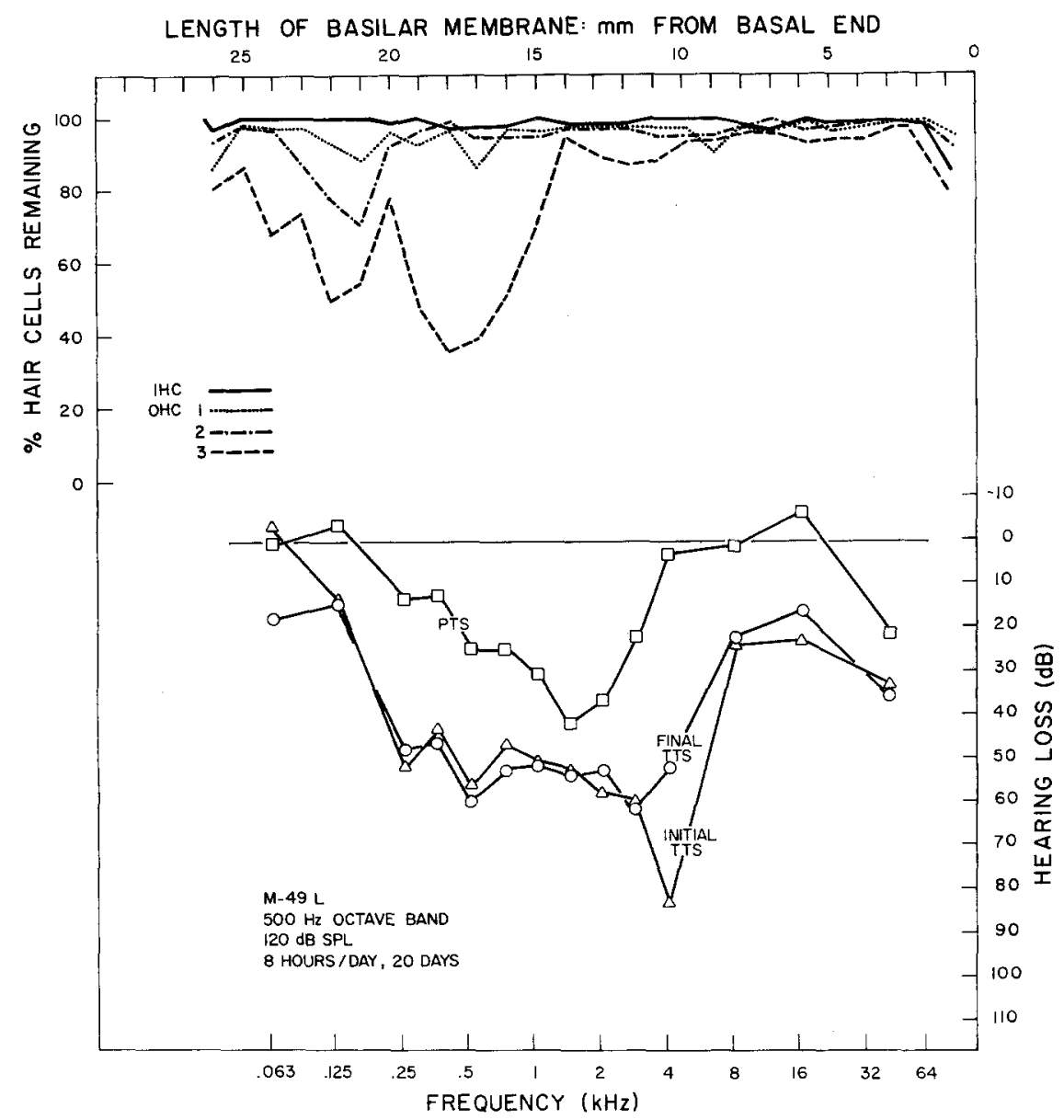

Fig. 1

Figs. 1-4. Audiograms (lower half) and cytocochleograms (upper half) for each ear of the two monkeys exposed to the $500-\mathrm{Hz}$ octave-band noise

\section{0-Hz Octave Band Exposures}

The data from monkeys exposed to the $500-\mathrm{Hz}$ octave band are presented in Figures $1-4$. The loss resulting from this exposure was, in all cases, quite broad, extending over at least four octaves in the $0.25-8-\mathrm{kHz}$ range. With the exception of an $82-\mathrm{dB}$ initial TTS at $4 \mathrm{kHz}$ for M-49 L, the maximum TTS values fell in the $57-73 \mathrm{~dB}$ range. This maximum temporary shift was generally found at frequencies above the center of the exposure band, in some cases as much as three octaves above. For M54 , the maximum PTS was at $2 \mathrm{kHz}$ for both ears, while for M-49, the maximum PTS was at $1 \mathrm{kHz}$ for the right ear and $1.4 \mathrm{kHz}$ for the left ear. 


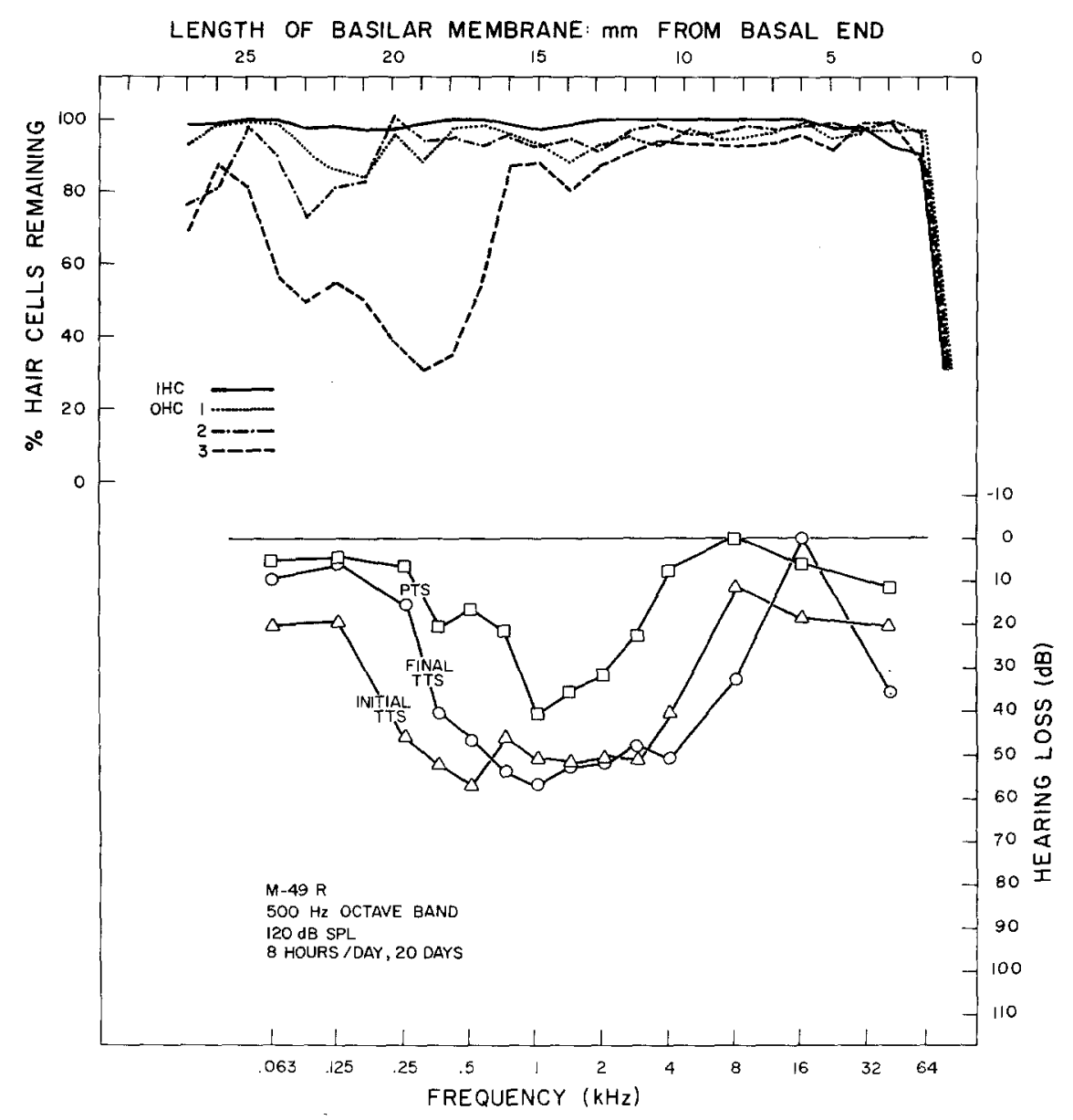

Fig. 2. (Leg. see p. 51)

At all but a few frequencies, the greatest effect of the exposure was seen in the initial data for TTS, which was either greater than, or approximately equal to, the final TTS. Only at $63 \mathrm{~Hz}$ was a PTS found to be greater than initial TTS in these animals. There were also only two instances where PTS was greater than the final TTS (M-49 R, $16 \mathrm{kHz}$ and $\mathrm{M}-54 \mathrm{~L}, 16 \mathrm{kHz}$ ).

The hair cell counts for these $500-\mathrm{Hz}$ exposure monkeys revealed a loss which was greatest for the third row of outer hair cells, with the second and first rows affected progressively less. The hair cell data for M-54 showed considerably less loss of third row outer hair cells than was seen in the data of $M-49$, even though the amount of behaviorally-determined hearing loss was comparable for the two animals. The inner hair cells remained unaffected by the exposure, except for loss in the first millimeter of the cochlea (juxtafenestral lesions, Johnsson and Hawkins, 1976; Hawkins et al., 1976). 


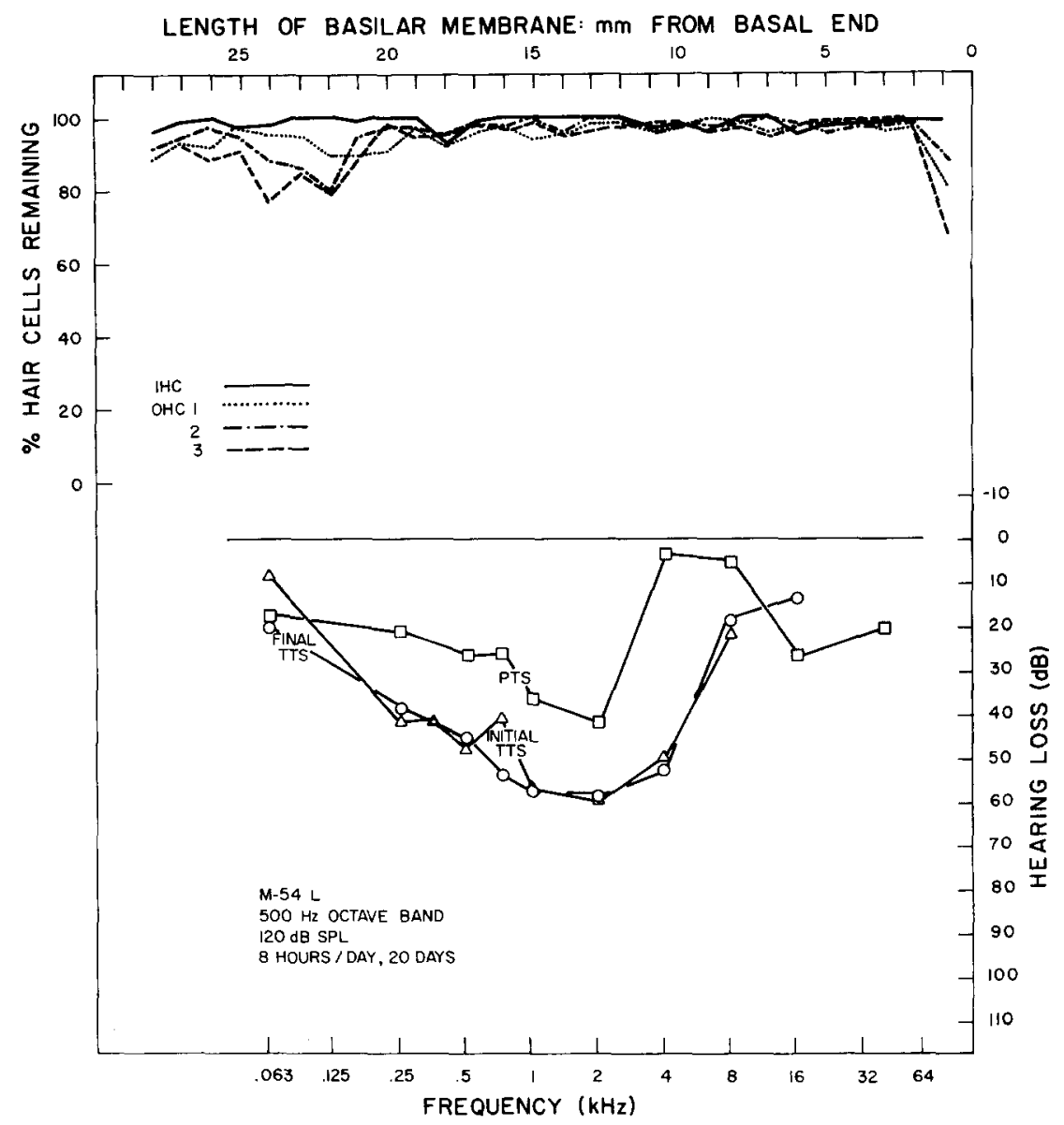

Fig. 3. (Leg. see p. 51)

\section{2-kHz Octave Band Exposures}

Figures $5-8$ present data for the animals exposed to the $120-\mathrm{dB}, 2-\mathrm{kHz}$ octave band for 20 days. As with the $500-\mathrm{Hz}$ exposure animals, relatively broad losses were found. The amount of the loss was more severe with this group, with TTS values exceeding $100 \mathrm{~dB}$ in some cases and PTS values in the 50-70 dB range. There was less tendency in these animals for the frequency of maximum TTS to be shifted above the center of the exposure band; in the case of M-53, there was even some shift downward. Where there was an upward shift, it was never greater than one octave. In all cases, however, the losses were asymmetrical towards higher frequencies, i.e., there was greater overall loss above $2 \mathrm{kHz}$ than below. For M-53, maximum permanent shift occurred at $2 \mathrm{kHz}$ in the left ear and almost equally at 1.4 and $2.8 \mathrm{kHz}$ in the right. For M-56, the maximum PTS was at $4 \mathrm{kHz}$. 


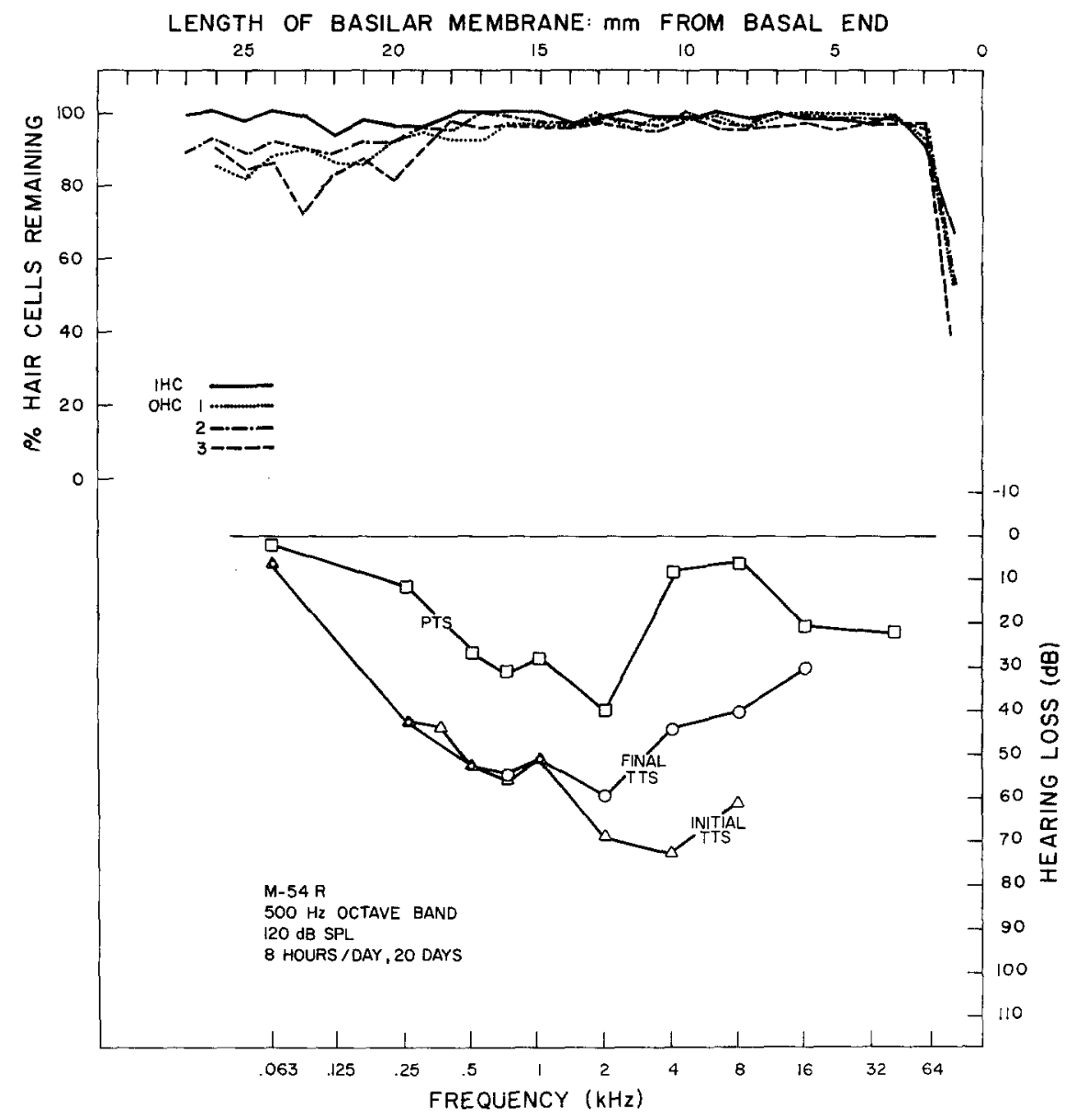

Fig. 4. (Leg. see p. 51)

As was also seen in the $500-\mathrm{Hz}$ exposure animals, initial TTS tended to be somewhat greater than final TTS at most frequencies. TTS was always greater than PTS, with the exception of the $32-$ and $40-\mathrm{kHz}$ data from M-53 R, where no recovery occurred following the end of exposure. For frequencies below $0.5 \mathrm{kHz}$ in the PTS data of $\mathrm{M}-53$, there was a $10-\mathrm{dB}$ or greater improvement in threshold relative to baseline. This effect was also noted in the data of other monkeys and is not believed to be measurement error.

The histology from M-53 showed that the greatest effect was on the third row of outer hair cells, with minimal loss in the first and second rows. A similar pattern was seen in the right ear of M-56, although all rows showed some loss. The regions not plotted in the hair-cell data of M-56 represent artifacts from the fixation process which precluded counting cells in those regions. The severe loss of cells at the 13$\mathrm{mm}$ point in the left ear of M-56 was a finding which was unique. No such loss was observed in any other animal. There was no corresponding extreme loss in behav- 


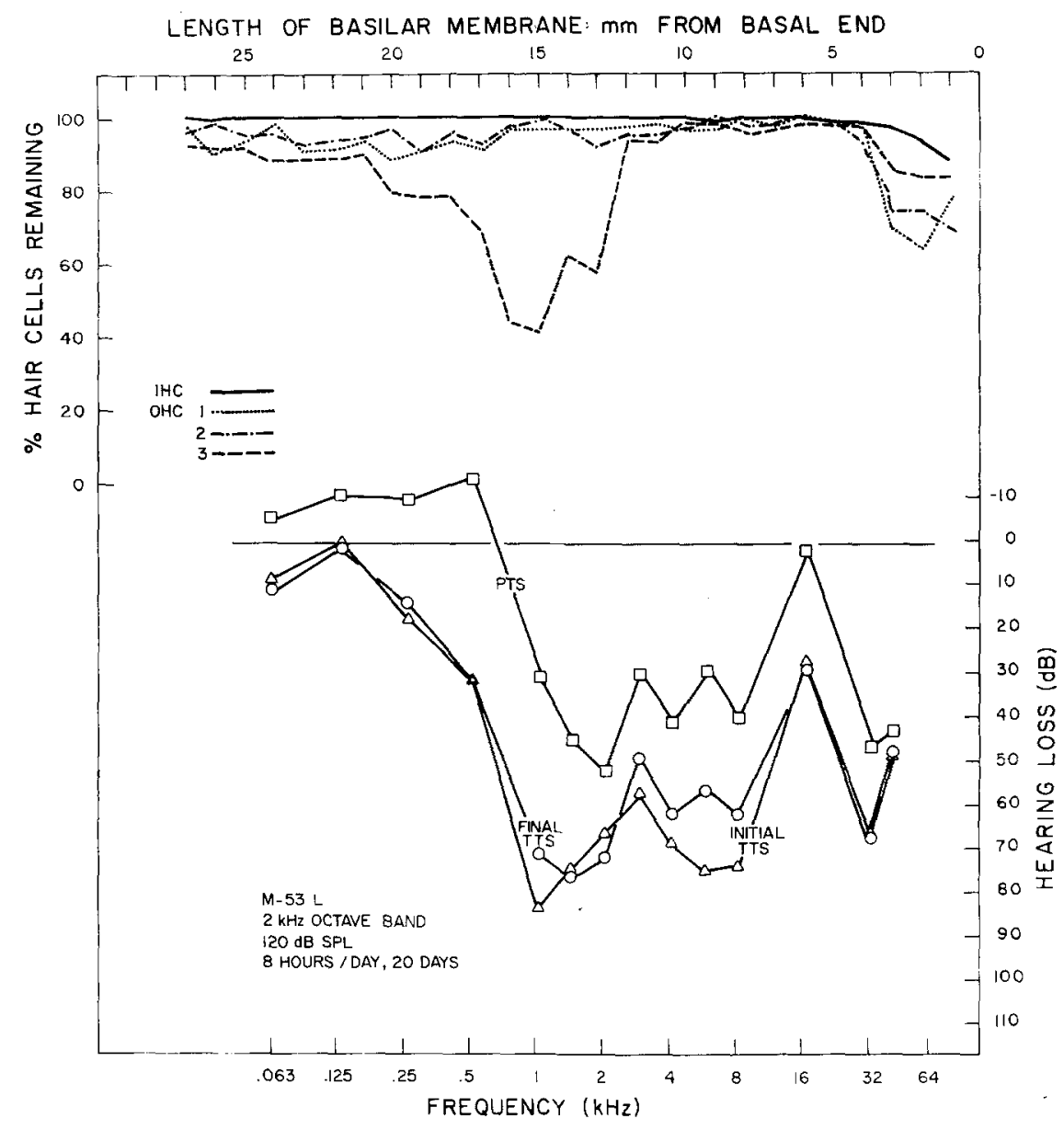

Fig. 5

Figs. 5-8. Audiograms (lower half) and cytocochleograms (upper half) for each ear of the two monkeys exposed to the $2-\mathrm{kHz}$ octave-band noise

ioral sensitivity. The complete loss of all cells in the lower basal turn occurred in the right ears of both of these animals, and to a lesser extent, in the left ear of M56.

Data from M-55 the monkey exposed to the $2-\mathrm{kHz}$ band for $40 \mathrm{~h}$ continuously, are shown in Figures 9 and 10. Since there was only one exposure period, initial and final TTS measurements are identically defined; hence only one TTS function has been shown. The amount of TTS for this animal was $80-90 \mathrm{~dB}$, about the same as that seen in M-53, and slightly less than the TTS for M-56. The frequencies at which TTS occurred were about the same for $\mathrm{M}-55$ as for the other two $2-\mathrm{kHz}$ exposure animals, but there was less PTS in terms of both maximum shift and frequencies affected. Except for a maximum TTS at $1.4 \mathrm{kHz}$ for the right ear, all functions showed a maximum at the $2-\mathrm{kHz}$ center of the exposure band. 


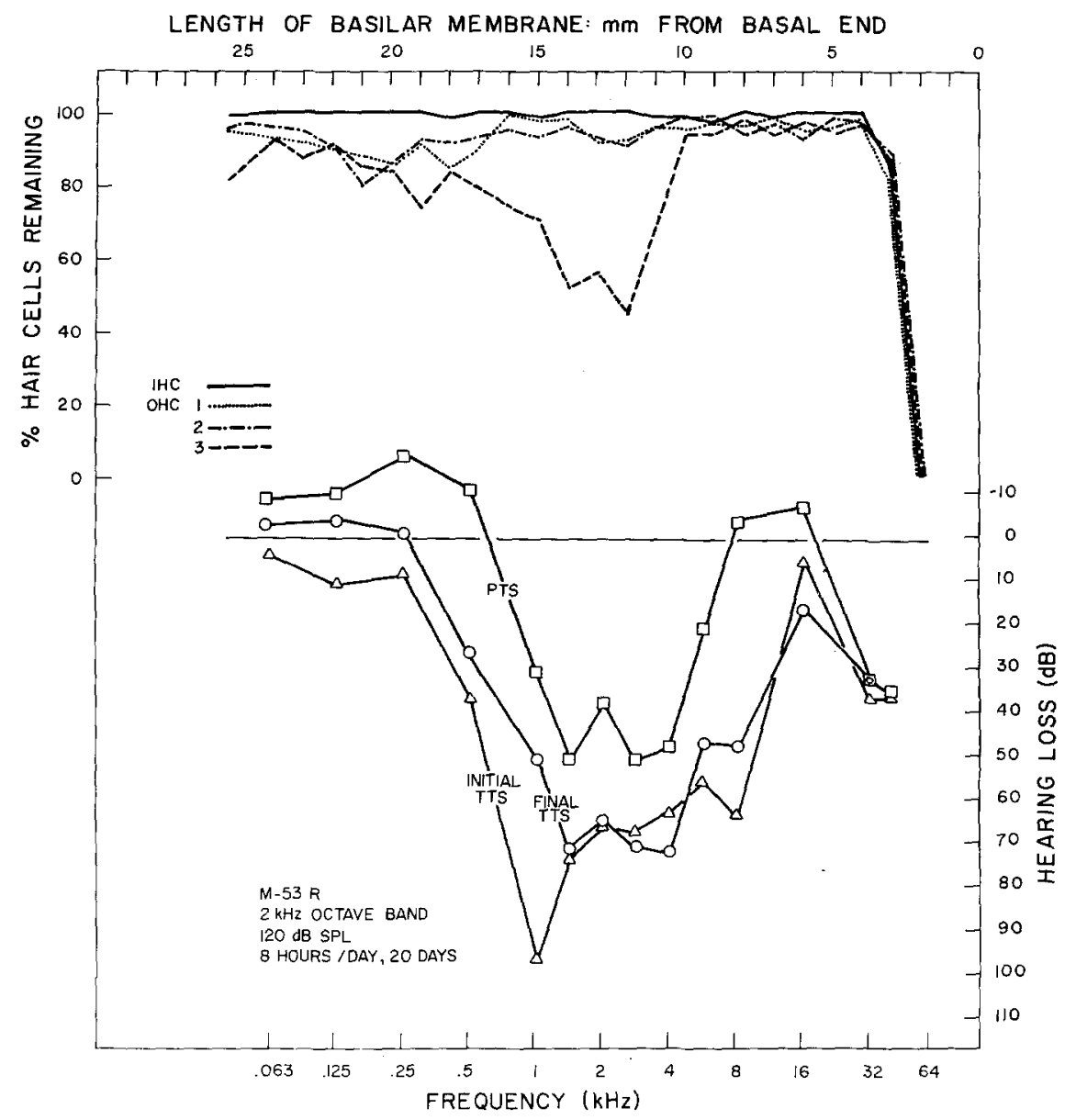

Fig. 6. (Leg. see p. 55)

The hair cell data from M-55 L showed a discrete lesion in the $14-15 \mathrm{~mm}$ region of the membrane, with some involvement of inner hair cells. The first row of outer hair cells showed a slightly greater loss than either of the other two rows. The right ear of this animal showed no loss of cells, with the exception of a $40 \%$ loss of outer hair cells in the 1 st $\mathrm{mm}$, which was also seen in the left ear.

\section{4-kHz Octave Band Exposures}

Data from monkeys exposed to the 4-kHz octave band are shown in Figures 11-14. The frequency range of the hearing losses shown by these animals tended to be narrower; usually no loss was seen below $1 \mathrm{kHz}$. Maximum TTS values were in the 80-90 dB range and were found at, or an octave or less above, the 4-kHz center of the exposure band. The maximum final TTS for M-71 $\mathrm{R}$ may be as high as 11.2 


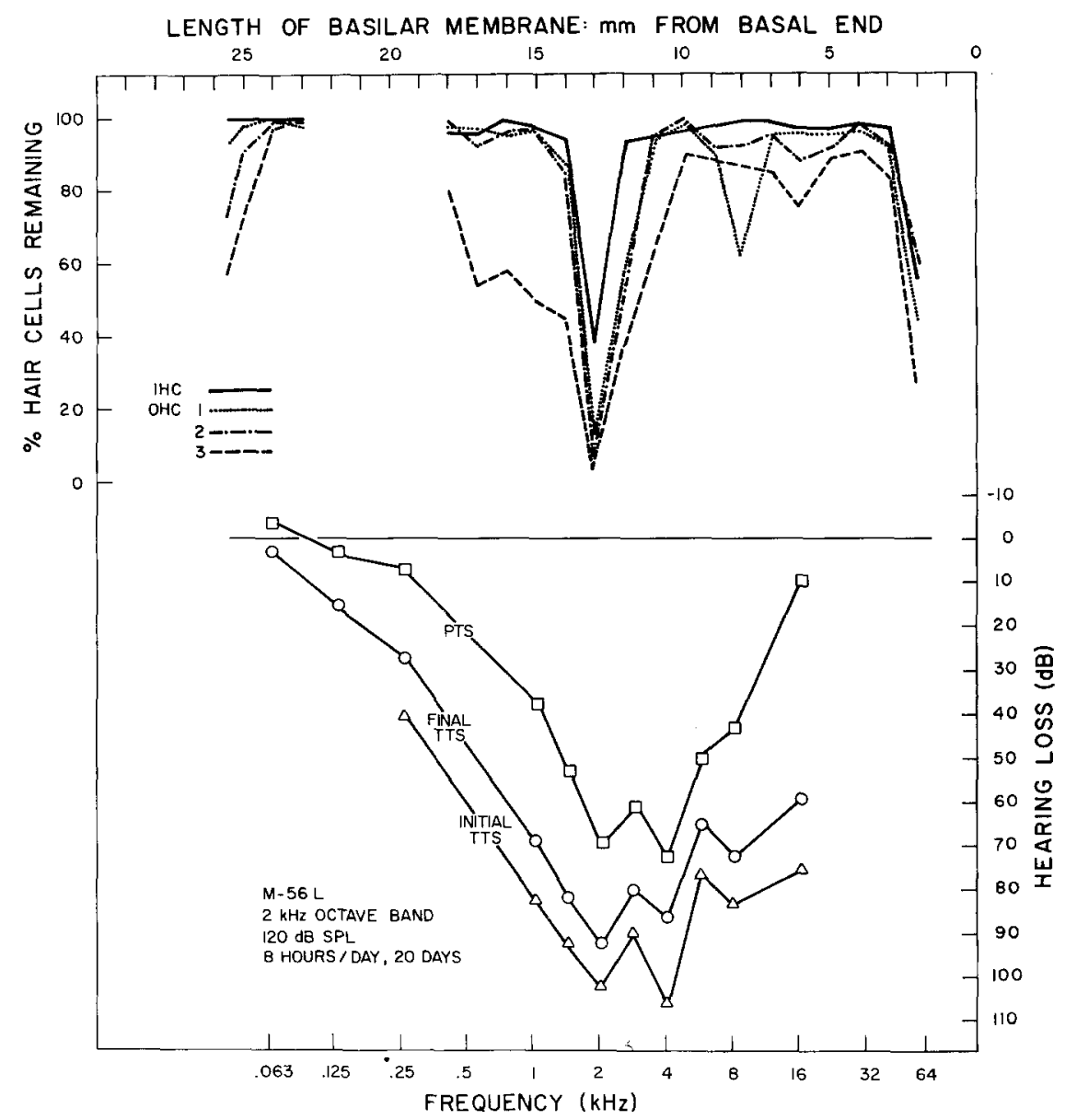

Fig. 7. (Leg. see p. 55)

$\mathrm{kHz}$, but that function is reasonably flat in the $2-11.2 \mathrm{kHz}$ region, making a maximum difficult to specify. Maximum PTS was within the exposure band with the possible exception of M-71 R. In the case of M-71 L the maximum was actually below the center of the band. The PTS function for M-71 $\mathrm{R}$ was reasonably flat and did not have a well-defined maximum.

In the data from M-71, the initial TTS again tended to be greater than the final TTS, but in the M-68 data, this effect was not seen. There was a particularly strong reversal in this tendency in the frequencies below $2 \mathrm{kHz}$ in the left ear. At frequencies between 2 and $16 \mathrm{kHz}$ where threshold shifts were greatest, PTS was always less than TTS, but at other frequencies, that relationship was not always true.

The hair-cell counts for M-68 revealed a loss of outer hair cells in all three rows. In the left ear of $\mathrm{M}-68$, the third row was most affected in the $12-15 \mathrm{~mm}$ region, with all three rows showing approximately equal losses in other regions. The right ear of this animal showed approximately equal losses of outer hair cells in the 11-15 


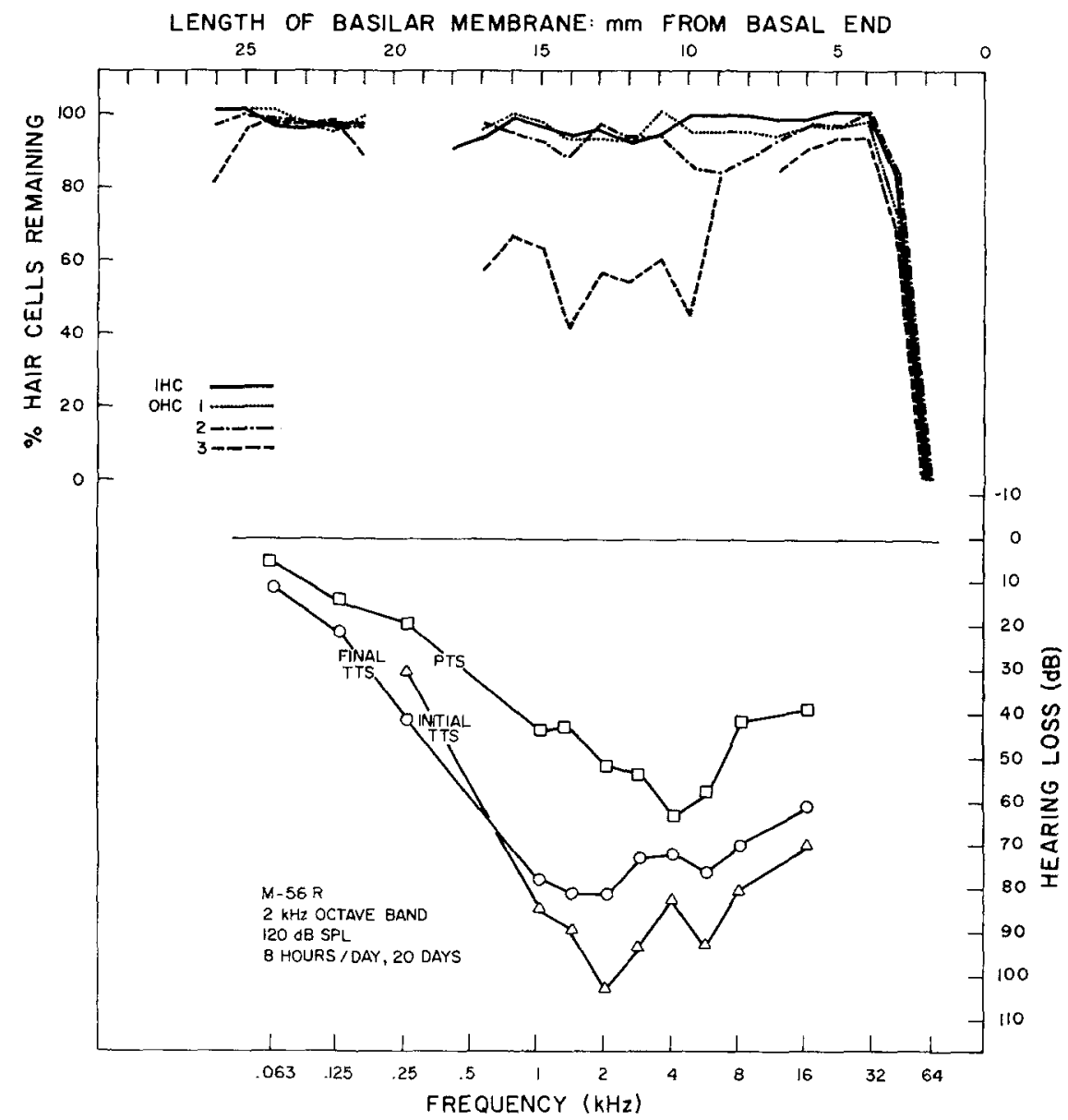

Fig. 8. (Leg. see p. 55)

mm region of the membrane and did not show as severe a loss in the extreme basal end as was seen in the left ear. The left ear of M-71 showed loss of all three rows of outer hair cells in the $2-4 \mathrm{~mm}$ region, but the locus of this loss was much lower than would be expected from the behaviorally-determined hearing loss. No cytocochleogram is available for the right ear of $\mathbf{M}-71$, which was saved for electron microscopy.

\section{8-kHz Octave Band Exposures}

Figures $15-18$ present the $8-\mathrm{kHz}$ exposure data. The width of these losses resembled that of the 4-kHz animals. Maximum TTS was in the 70-100 dB range, and was usually at the $8-\mathrm{kHz}$ center of the exposure band. Maximum PTS was within $\pm 1 / 2$ octave of $8 \mathrm{kHz}$. M-66 also showed an extreme PTS at $32 \mathrm{kHz}$ in both ears which was greater than the PTS centered at $8 \mathrm{kHz}$. 


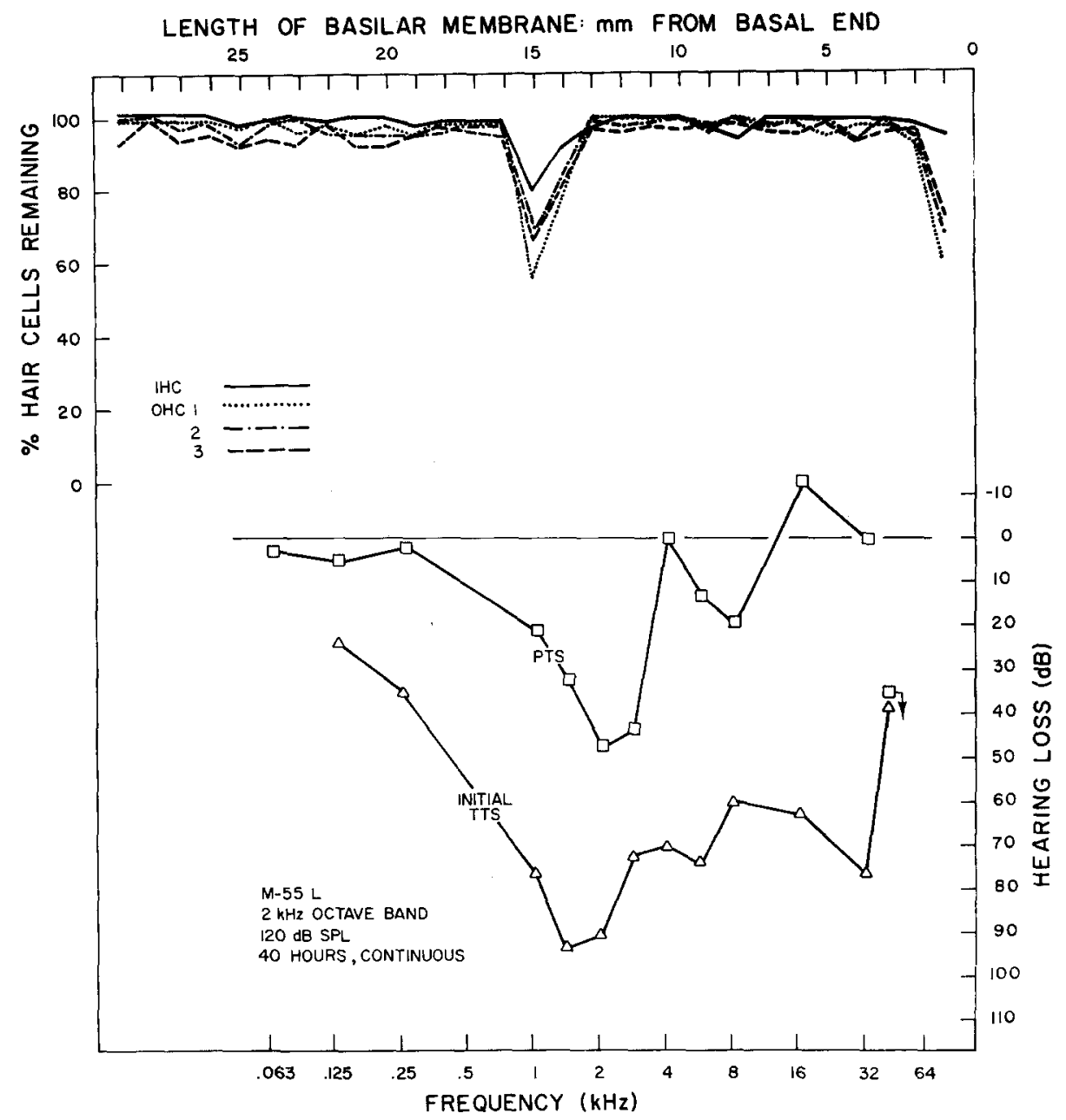

Fig. 9

Figs. 9-10. Audiograms (lower half) and cytocochleograms (upper half) for each ear of the monkey exposed to the $2-\mathrm{kHz}$ octave-band noise for $40 \mathrm{~h}$ continuously

Initial TTS tended to be greater than final TTS in the data of M-41, but this relationship did not hold in the M-66 data. For frequencies between 4 and $32 \mathrm{kHz}$, PTS was always less than TTS in these animals.

The hair cell data from M-41 showed a loss in all three rows of outer hair cells, and some loss of inner hair cells at the 9-mm locus on the membrane. The right ear from this animal showed a similar pattern, but it also showed loss of all cells in the extreme basal turn. In the data of M- $66 \mathrm{~L}$, the third row of outer cells showed the greatest loss, followed respectively by the second and first rows. The right ear data from this monkey showed a similar pattern, with slightly more loss at the extreme basal end. 


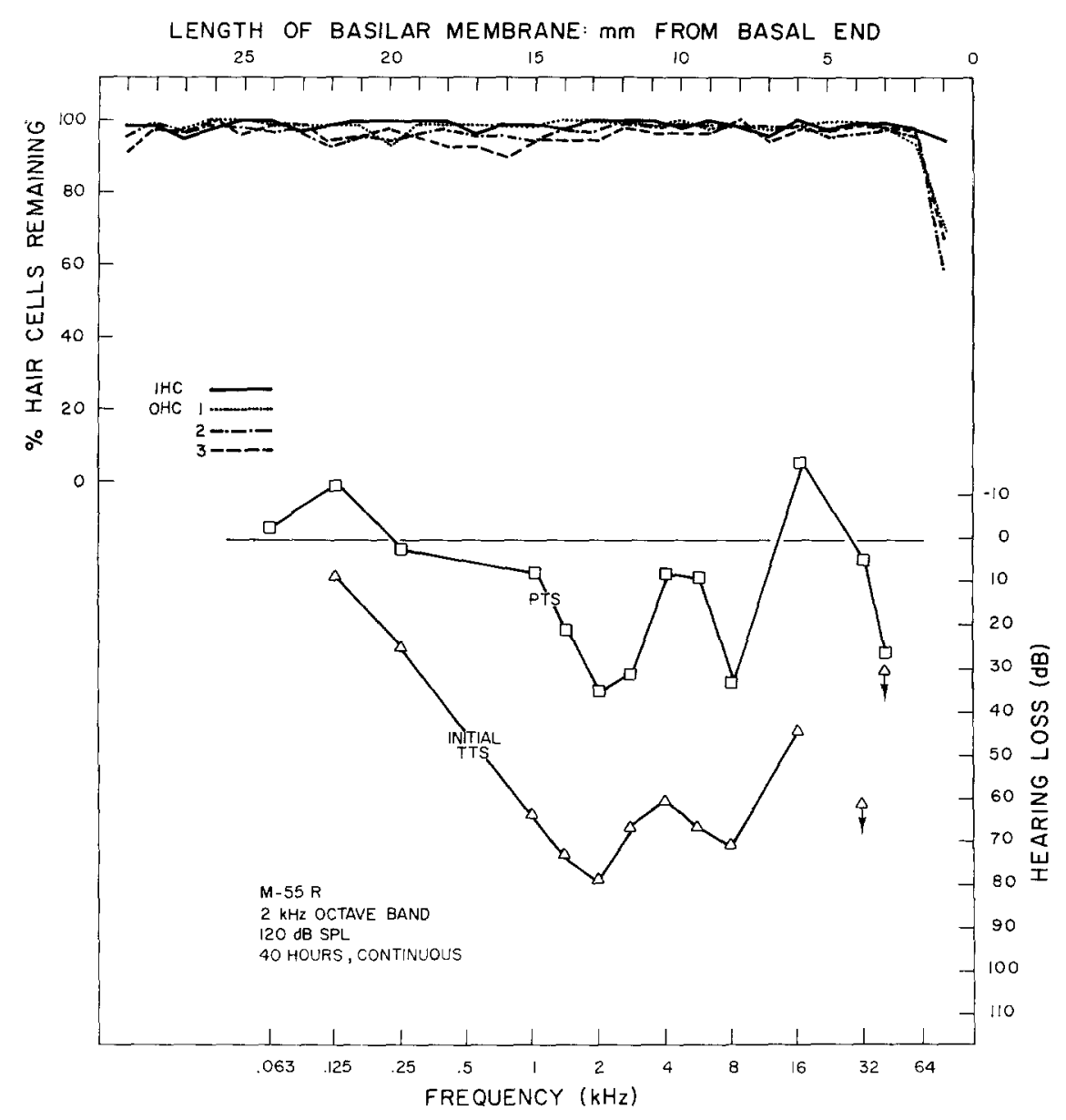

Fig. 10. (Leg. see p. 59)

\section{Wide-Band Exposures}

Data from the animals exposed to the wide-band noise are presented in Figures 19-22. A moderately broad loss was produced, but it was not significantly greater than some of the losses seen in the $500-\mathrm{Hz}$ and $2-\mathrm{kHz}$ exposure animals. The amount of TTS $(80-100 \mathrm{~dB})$ was greater for these animals than for the $500-\mathrm{Hz}$ group, but about the same as for the $2-\mathrm{kHz}$ group. The maximum PTS was in the $40-60 \mathrm{~dB}$ range, i.e., about the same as that seen in all other groups. The frequency at which this maximum occurred was $2 \mathrm{kHz}$ for $\mathbf{M}-34$ and $8 \mathrm{kHz}$ for $\mathrm{M}-63$. For $\mathbf{M}$ 34, initial TTS tended to be greater than final TTS in the left ear, but the two functions were about the same in the right ear. M- 63 was run on a slightly different testing protocol during his final exposure week and final TTS data could not be directly compared to those of other animals. 


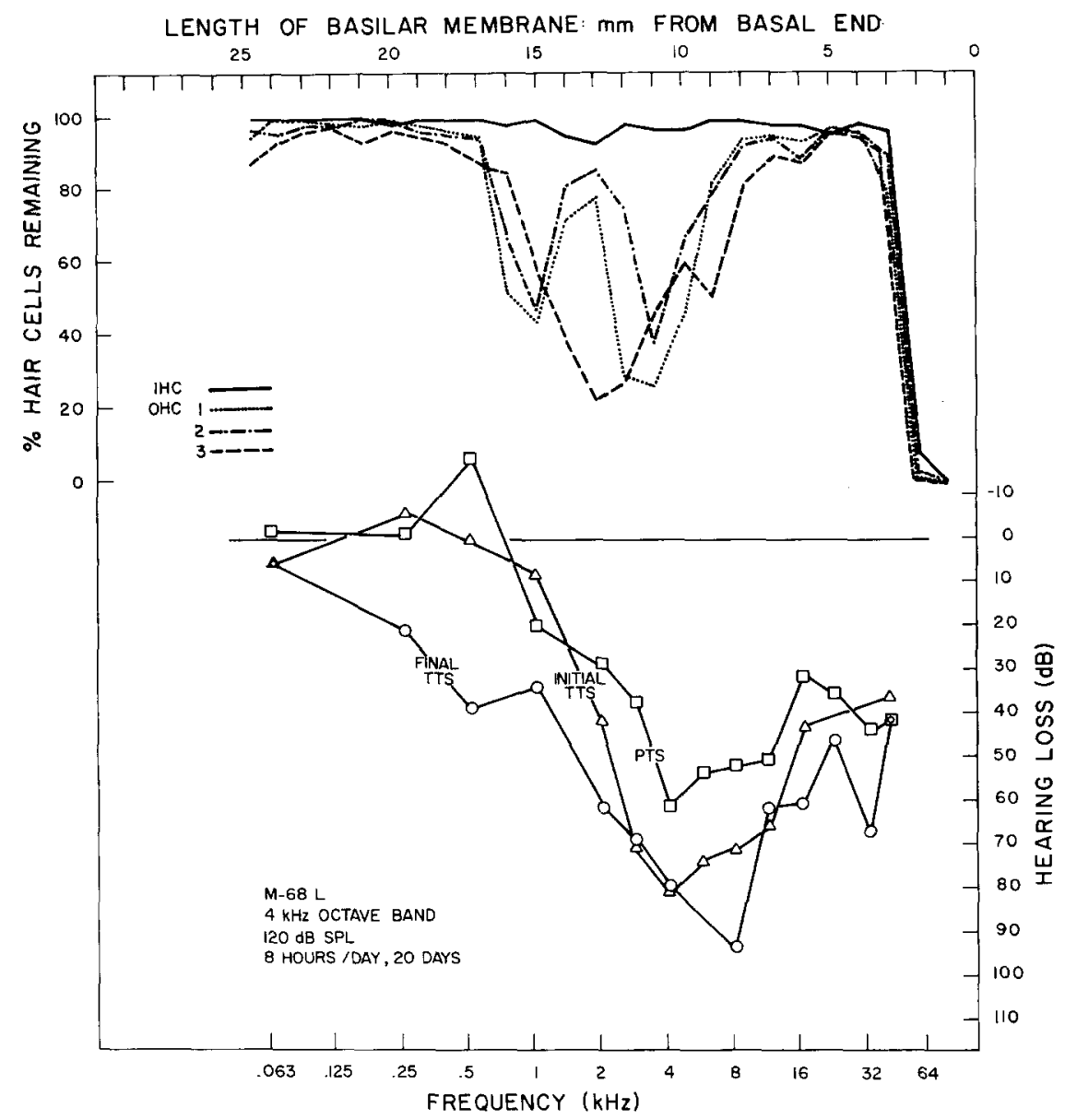

Fig. 11

Figs. 11-14. Audiograms (lower half) and cytocochleograms (upper half) for each ear of the two monkeys exposed to the $4-\mathrm{kHz}$ octave-band noise. The cytocochleogram data are not available for $\mathrm{M}$ $71 \mathrm{R}$

The histology for these animals showed considerably more loss than for any other group. In all cases the third row of outer hair cells showed the greatest loss. In the data for M-34, the remaining two rows of outer hair cells showed approximately equal loss, with a suggestion in the right ear of greater loss in the first row than in the second. In the data from $M-63$, there is a clear gradation of effect from third to second to first rows, except in the extreme basal turn. M-63 L showed the most severe basal turn lesions seen in any ears.

\section{Discussion}

A surprising finding of the present study was the lack of an increase in TTS with continued exposure. Apparently under these exposure conditions, maximum TTS 


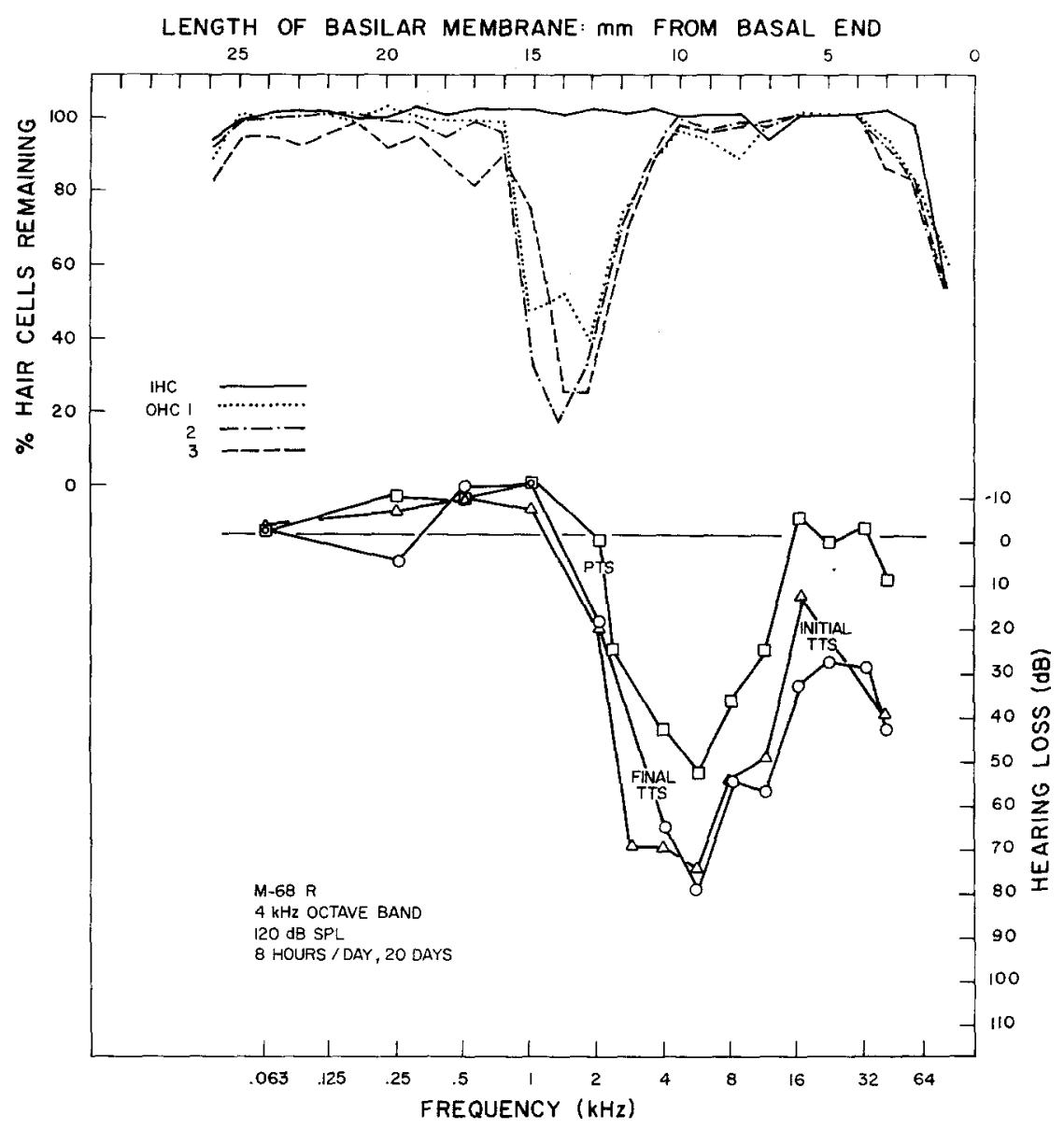

Fig. 12. (Leg. see p. 61)

occurs within the first $8 \mathrm{~h}$ in the noise. Only rarely was a final TTS recorded which was greater than initial TTS. This finding is reminiscent of asymptotic TTS such as reported by Melnick (1976) and Melnick and Maves (1974) in man and by Mills (1976) in the chinchilla; that is, TTS increases to some point, and then remains relatively stable with continued exposure.

Although TTS does not increase with longer exposures, it is unclear whether there is increasing permanent damage occurring. To a limited extent, the results from M-55, the animal continuously exposed to the $2-\mathrm{kHz}$ octave band for only $40 \mathrm{~h}$, provide some data bearing on this question. The TTS measured from this animal was quite similar to the TTS measured from the other $2-\mathrm{kHz}$ exposure animals, but the amount of PTS was much less. Although these results represent only a single animal and a different exposure schedule, it is nonetheless tempting to speculate that the additional $120 \mathrm{~h}$ that the other $2-\mathrm{kHz}$ animals spent in the noise did indeed produce more PTS than would have been observed had the exposure been only $40 \mathrm{~h}$. 


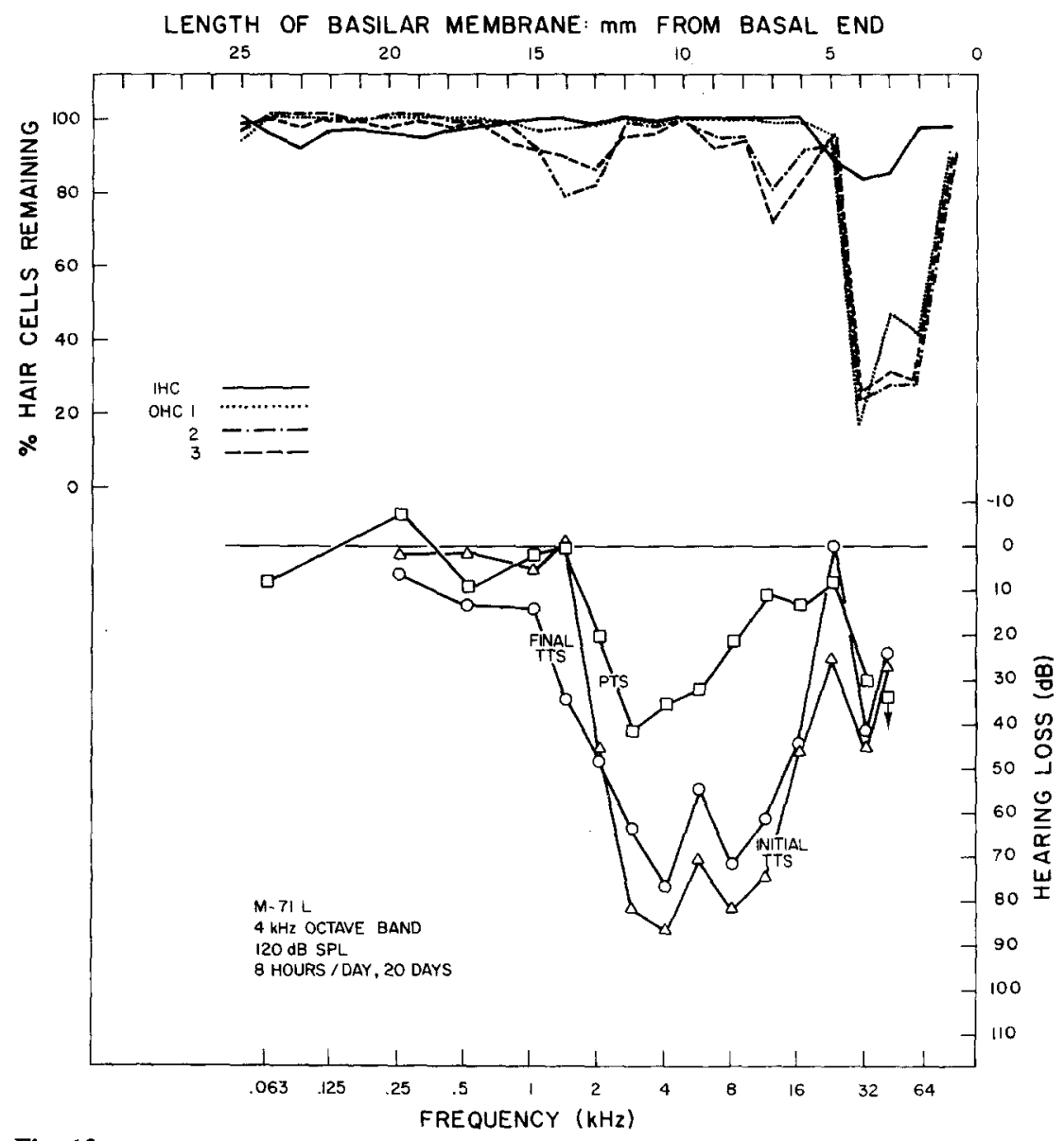

Fig. 13

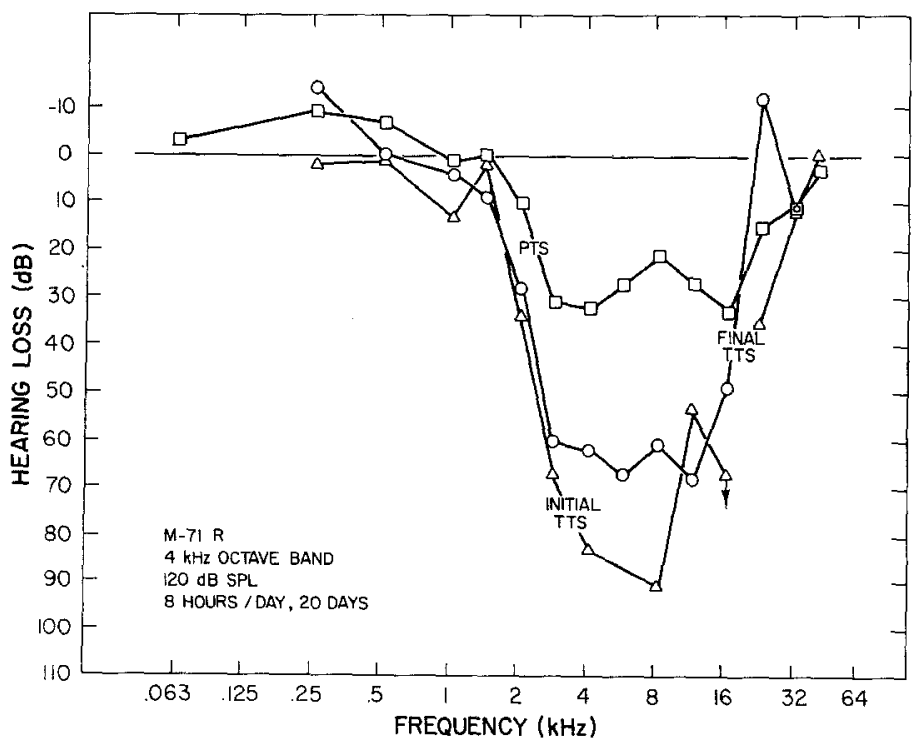

Fig. 14. (Leg. to Fig. 13 and 14 see p. 61) 


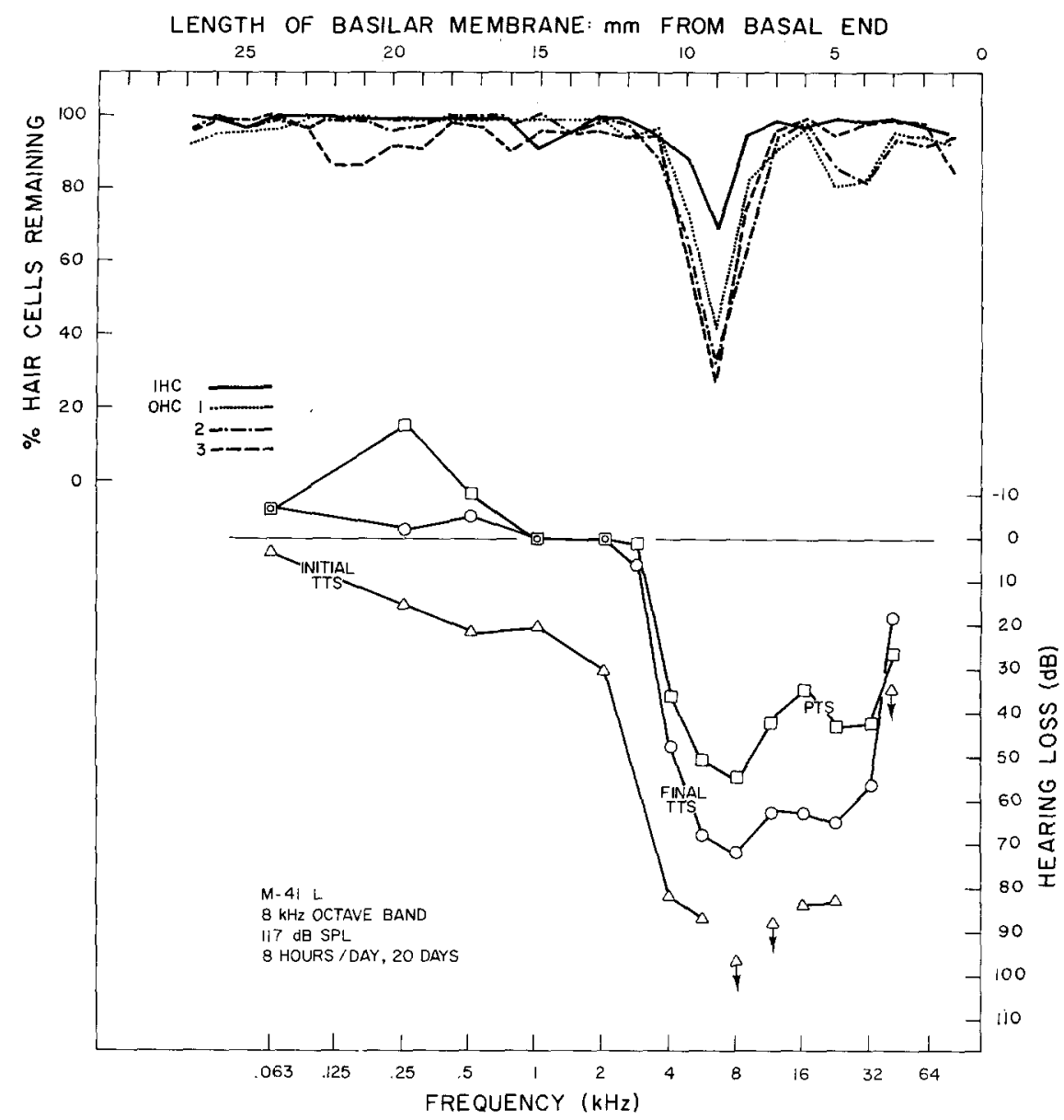

Fig. 15

Figs. 15-18. Audiograms (lower half) and cytocochleograms (upper half) for each ear of the two monkeys exposed to the $8-\mathrm{kHz}$ octave-band noise

Since TTS remained relatively constant or, in many cases, decreased during the 4 weeks of exposure in all the animals in this study, any attempt to predict amount of PTS from the TTS data would be likely to predict a non-increasing PTS as well. The data from M-55 suggest, however, that PTS may increase, and thus that TTS may be an inadequate predictor of PTS, at least for specifying the exact amount of the permanent impairment.

In most of the animals in the 160-h exposure group, however, the general shape of the final TTS function provides a fairly good estimate of the shape of the PTS function. In 14 of the 20 ears from these animals, the maximum PTS was within $1 / 2$ octave of the final maximum TTS. For six of the ten animals, the amount of recovery from the final TTS to PTS functions was $20-30 \mathrm{~dB}$ at many of the mid-range frequencies. In some animals, considerably more recovery was observed. 


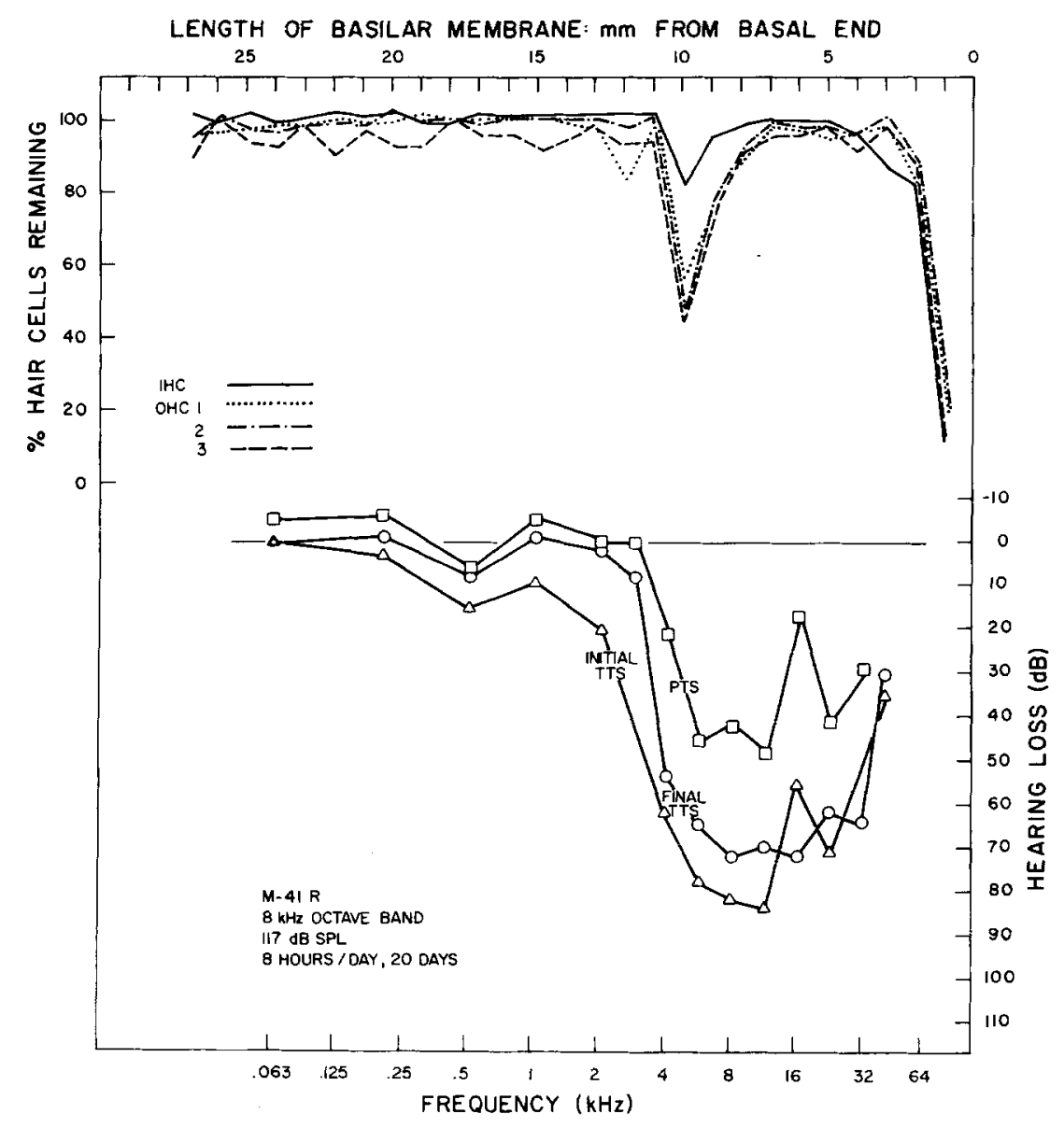

Fig. 16. (Leg. see p. 64)

In their classic study on TTS following exposure to intense sound, Davis et al. (1950) concluded that, with pure tone exposures, $500 \mathrm{~Hz}$ results in considerably less TTS than 1,2, or $4 \mathrm{kHz}$. They also concluded that the greatest hearing loss occurs at a frequency about $1 / 2$ octave above the exposure tone and that no significant elevation of thresholds was produced for frequencies below the exposure tone. Like the results of Davis et al., the present data also show considerably less effect, in terms of maximum loss, from the $500-\mathrm{Hz}$ exposure than from higher frequencies or from broad-band noise. Similar results have also been shown for the cat (Miller et al., 1963).

Clearly, from the present data, the Davis et al. conclusion that there is no significant loss below the exposure tone can be seen not to apply to long-duration exposures to bands of noise, at least in the monkey. Significant losses, both temporary and permanent, were produced below the exposure band. There was almost always a tendency, however, for there to be greater loss, in terms of area under the audiogram, above the center of the band than below. 


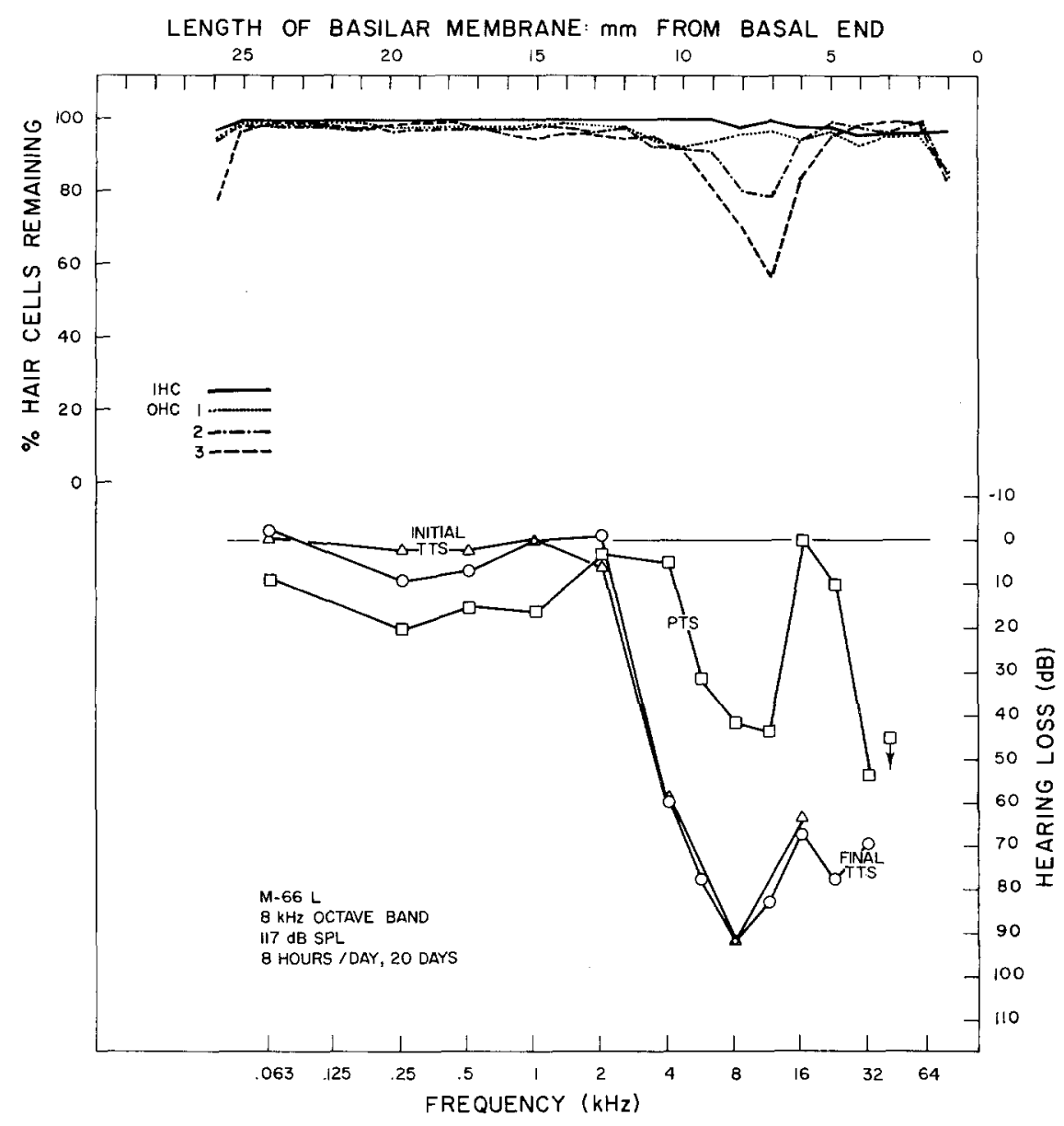

Fig. 17. (Leg. see p. 64)

The half-octave shift also is not as well defined as the findings of Davis et al. might imply. In the present study, low-frequency exposures tended to produce upward shifts in maximum loss of more than $1 / 2$ octave, while higher frequencies yielded less, if any, shift. Thus, the amount of upward shift from the center of the exposure band is related to the frequency at which the band is located. These results suggest the possibility of an area of the basilar membrane, located roughly in the $2-8 \mathrm{kHz}$ region, which is more susceptible to acoustic trauma. This area does not seem to be as well defined as it is in human beings; that is, acoustic trauma in the monkey is not necessarily characterized by a $4-\mathrm{kHz}$ "dip" in the audiogram as it is in man. Rather, in the monkey, the frequency spectrum of the exposure noise plays a primary role in determining the pattern of the hearing loss, but that pattern is also affected by the presence of the susceptible area on the membrane.

A second area of the membrane, which is apparently susceptible to damage by intense noise, is the lower basal turn, specifically the $0-4 \mathrm{~mm}$ region. Juxtafenestral 


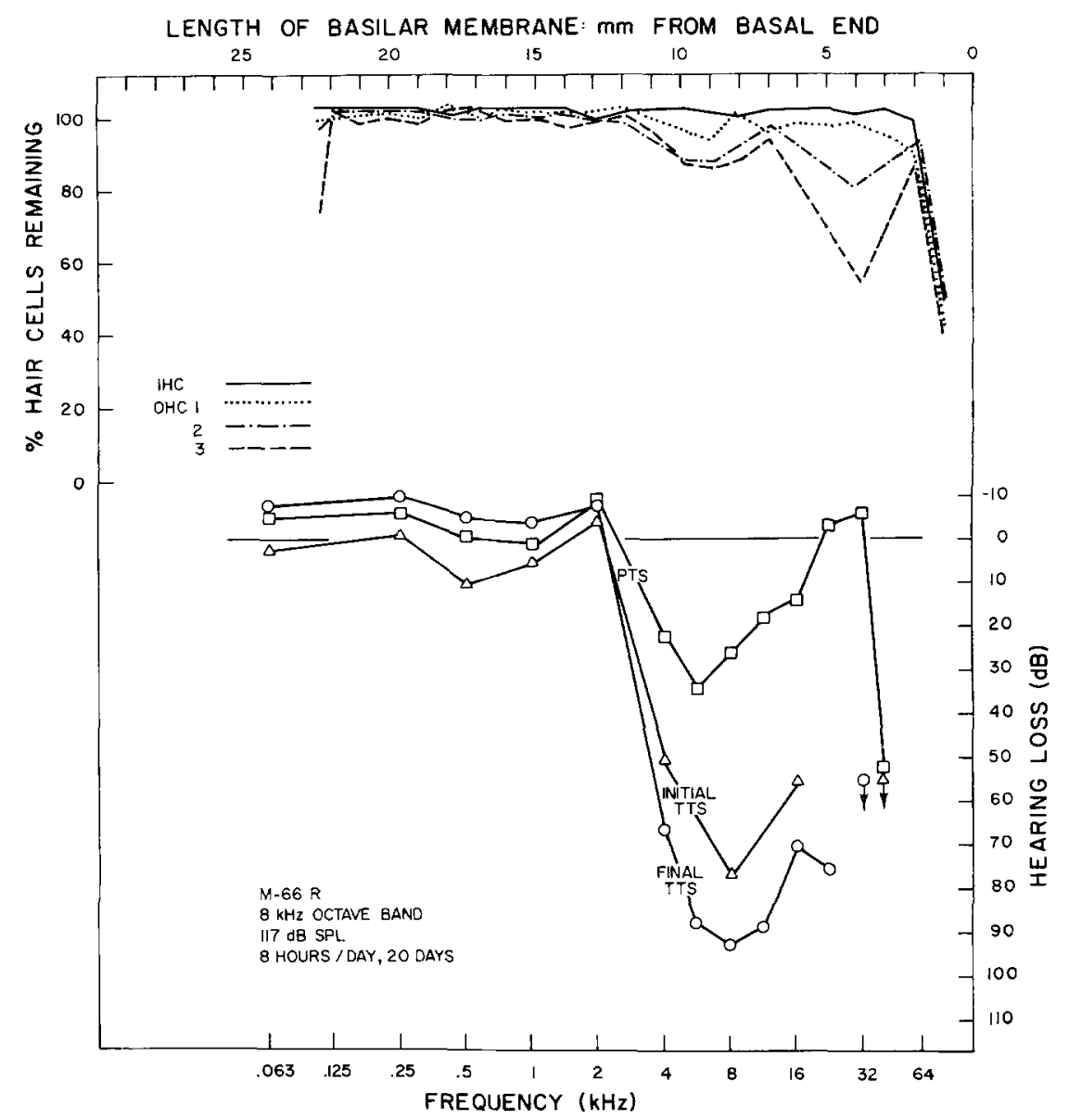

Fig. 18. (Leg. see p. 64)

lesions were seen in almost all of the ears, although not necessarily with concomitant hearing loss. In many cases, these lesions were more severe than those found above $5 \mathrm{~mm}$ from the base, and frequently involved complete loss of both inner and outer hair cells.

Although there was a reasonably good correspondence above $5 \mathrm{~mm}$ between the cochlear loci where tonotopical lesions occurred and frequencies at which there was PTS, the agreement is not as sharply defined as has previously been shown in monkeys with abrupt high-frequency hearing losses from ototoxic antibiotics (Stebbins et al., 1969). Those studies provided a tonotopic map of the monkey cochlea in which $2 \mathrm{kHz}$ was localized at about $15 \mathrm{~mm}$ from the base, $8 \mathrm{kHz}$ at $8 \mathrm{~mm}$, and 15 $\mathrm{kHz}$ at $4 \mathrm{~mm}$. In the figures presented here, a somewhat arbitrary positioning of the audiogram relative to the cytocochleogram was employed in which the $15-\mathrm{mm}$ point on the linear scale of the cochleogram was aligned with $1 \mathrm{kHz}$ on the log frequency axis of the audiogram. 


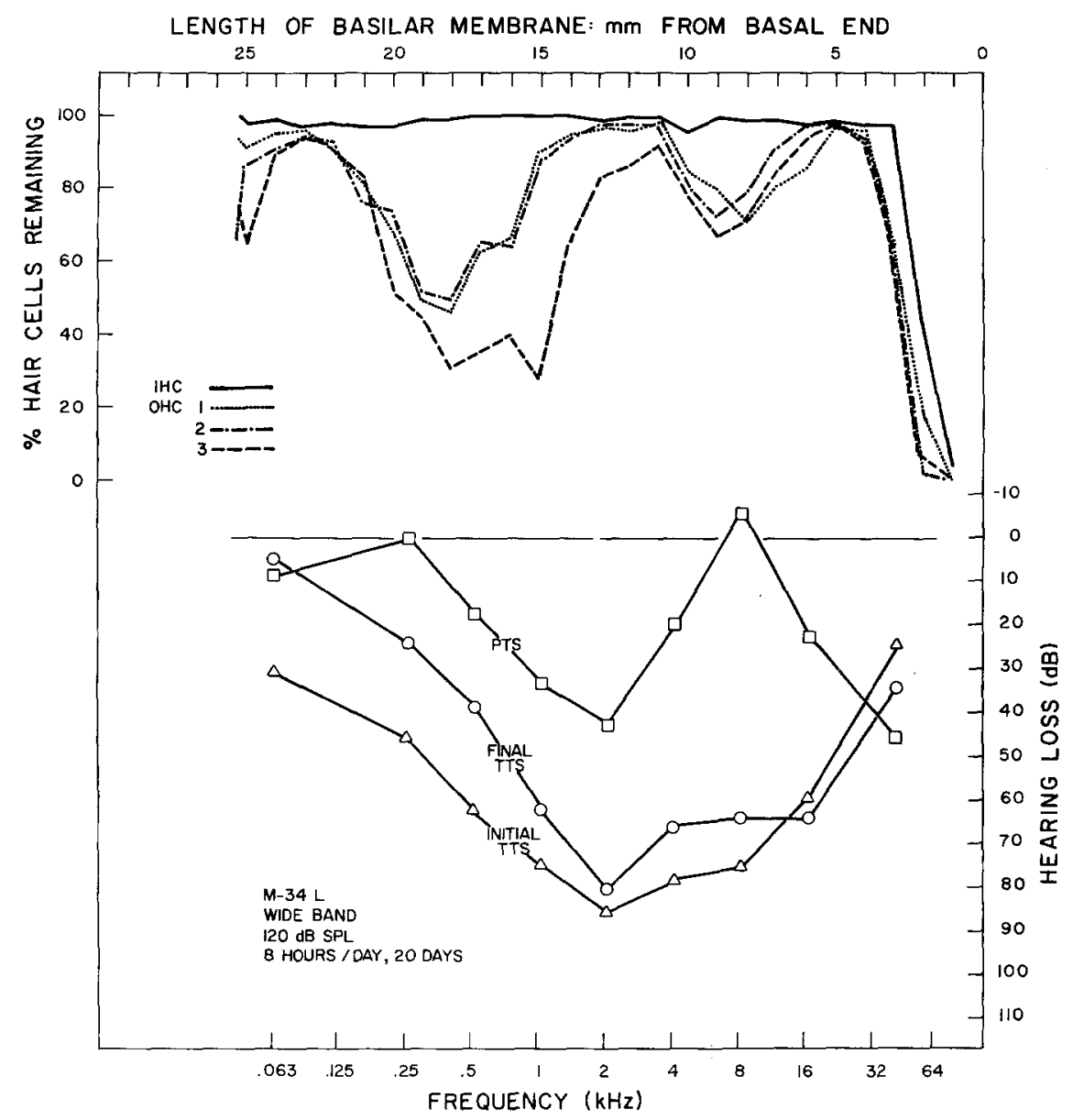

Fig. 19

Figs. 19-22. Audiograms (lower half) and cytocochleograms (upper half) for each ear of the two monkeys exposed to the wide-band noise

While the locus of cell loss in the cochlea was generally predictable, the magnitude of the loss was less than might be expected from the behavioral data. In M-49, M53 and M-56 R there were substantial shifts in threshold with loss of the third row of outer hair cells only. In M-54 and M-55 R there was PTS with almost no loss of hair cells. It is possible that this discrepancy reflects the occurrence of changes in the hair cells which result in loss of function of the cells, but which are not sufficient to count the cells as being absent.

Significant hearing loss with little or no pathology seen with the light microscope has also been reported in human beings who had a history of noise exposure (Wever, 1942; Bredberg, 1968) and in squirrel monkeys exposed to 120-dB pure tones (Hunter-Duvar and Elliott, 1972). The magnitude of the cell loss seen in the present 


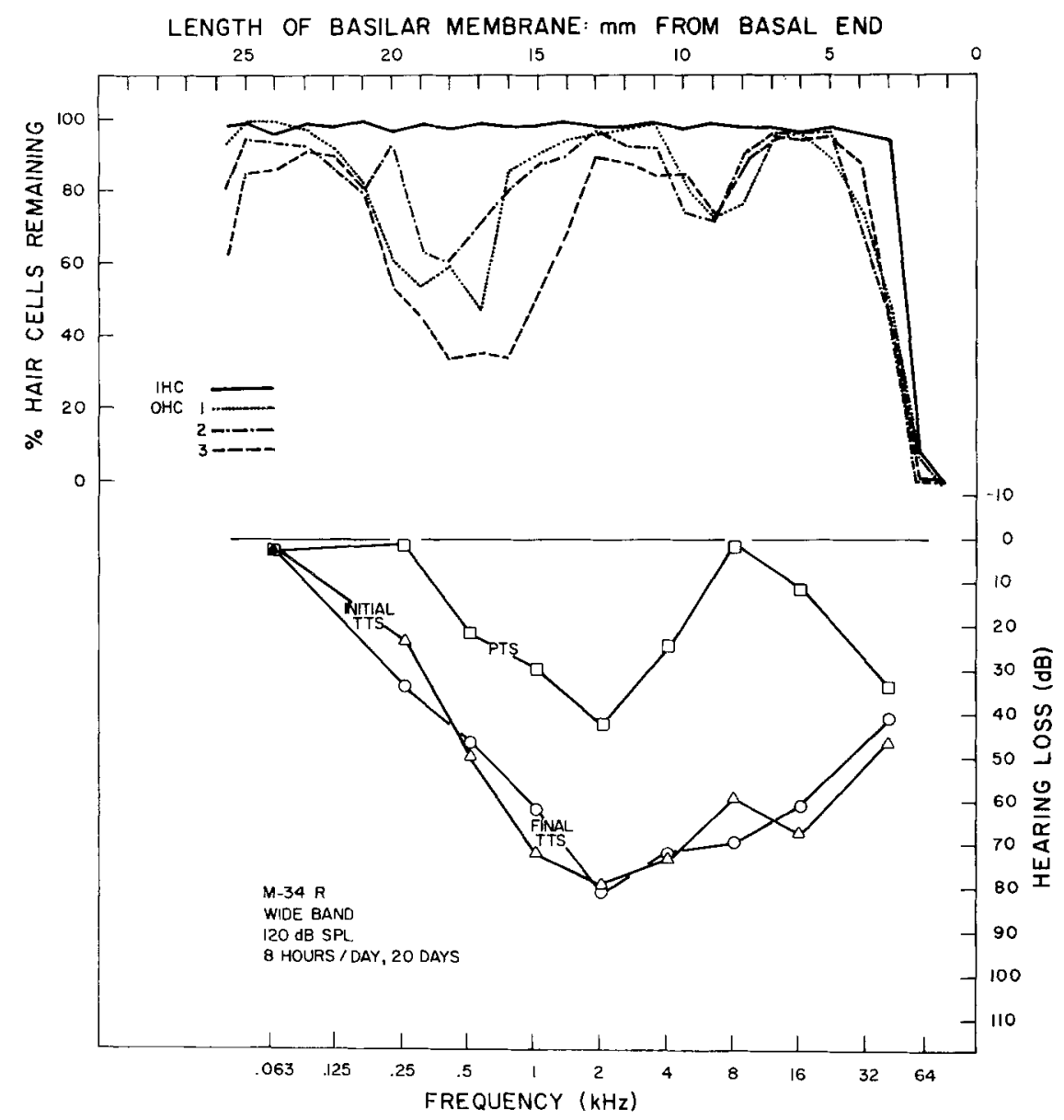

Fig. 20. (Leg. see p. 68)

animals is much less than has been reported in the chinchilla (Dolan et al., 1976; Ward and Duvall, 1971) and cat (Miller et al., 1963) following less severe exposures.

One final point which should be mentioned about the present data is a remarkable degree of symmetry between the ears, in terms of both audiograms and cytocochleograms. Most animals showed approximately the same amount and pattern of TTS and PTS in both ears. Hair cell loss also seemed to follow the same pattern on both sides. Animals which showed a loss of only third row outer hair cells in one ear showed a similar loss in the other, as did those animals with graded losses of all three rows. Exceptions occur in the data from M-56, the uniqueness of which was mentioned earlier, and to a small extent in the data of M-55 and M-68.

In summary, several findings from the present series of exposures should be 


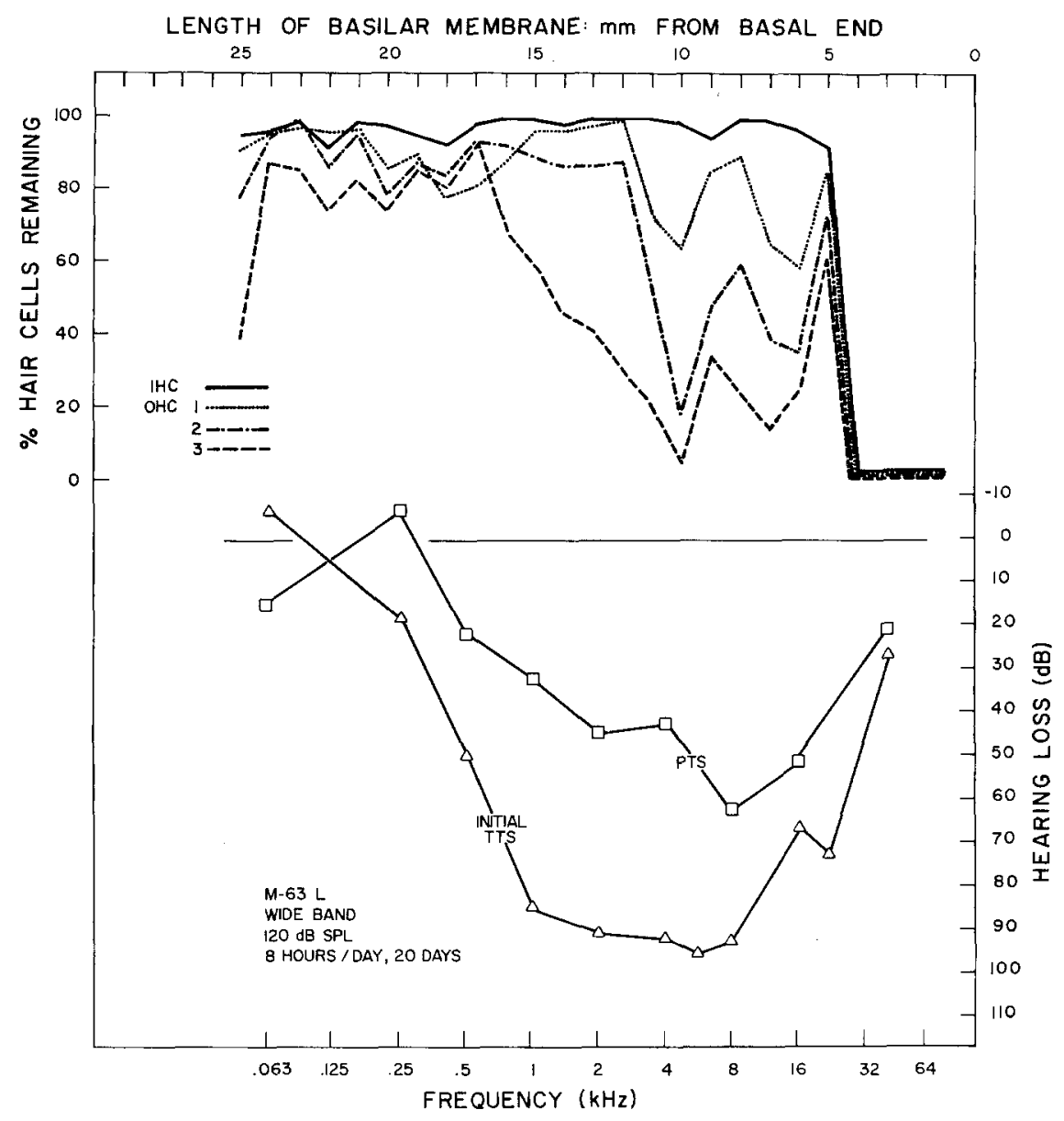

Fig. 21. (Leg. see p. 68)

emphasized. First, at the 117-120 dB levels employed, TTS did not seem to increase after the first $8 \mathrm{~h}$ of exposure, although increased permanent damage may have been occurring. Second, low-frequency exposures produced less hearing loss than did high-frequency exposures, but the loss was generally found more than $1 / 2$ octave above the center of the exposure band. With exposure bands of $2 \mathrm{kHz}$ and above, the maximum loss was generally within or just slightly above the band. Losses were usually asymmetrical towards the higher frequencies. Third, while hair cell loss generally occurred at the expected locations in the cochlea, it tended to be of a smaller magnitude than might be expected from the PTS functions. The exception was in the extreme basal turn, where severe lesions were quite commonly found without related high-frequency hearing loss. Finally, both ears of most animals were quite similar audiometrically and histologically. 


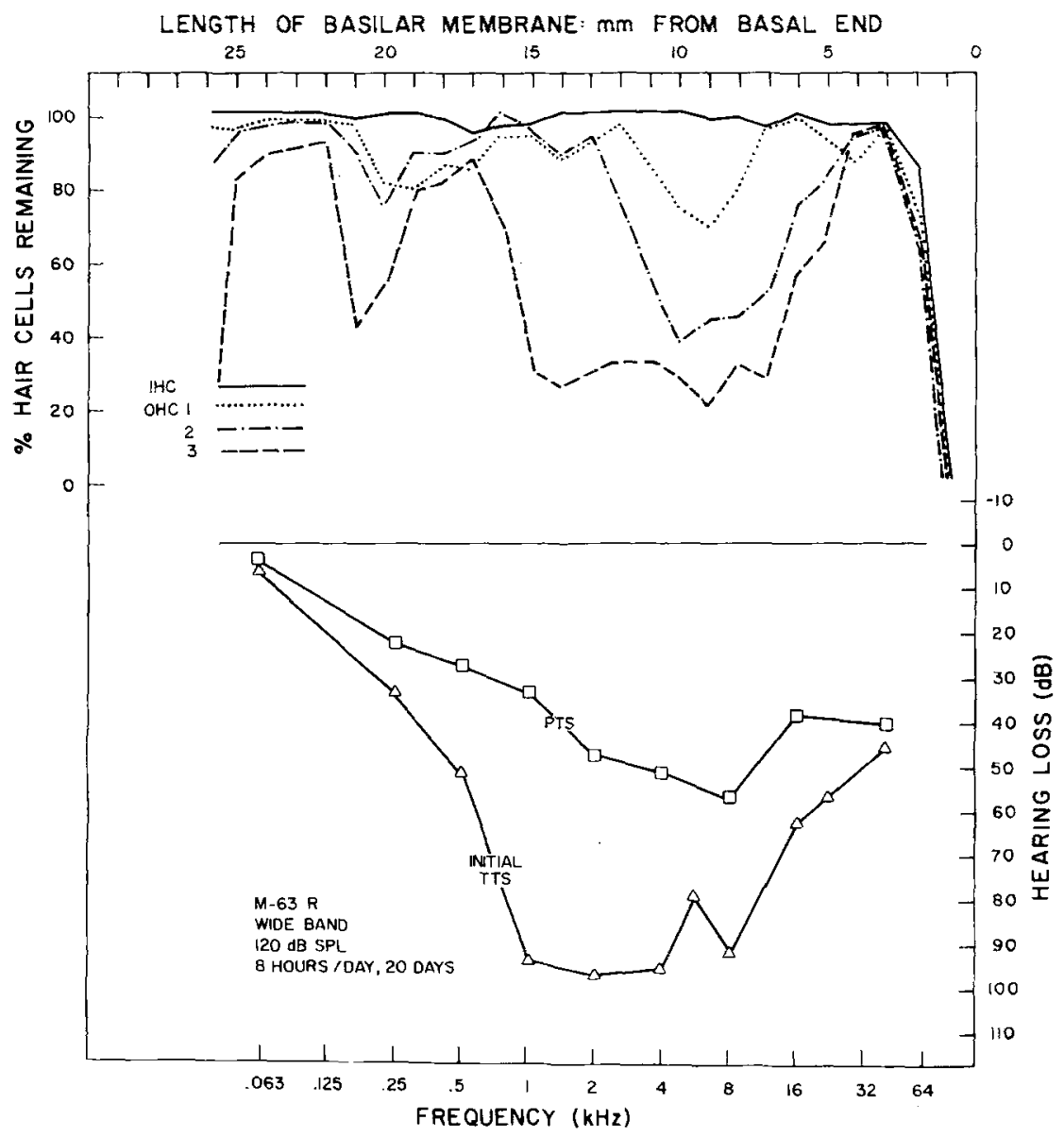

Fig. 22. (Leg. see p. 68)

\section{References}

Bredberg, G.: Cellular pattern and nerve supply of the human organ of Corti. Acta Otolaryngol., Suppl. 236, 1-135 (1968)

Davis, H., Morgan, C. T., Hawkins, J. E., Galambos, R., Smith, F. W.: Temporaty deafness following exposure to loud tones and noise. Acta Otolaryngol., Suppl. 88, 1-57 (1950)

Dolan, T. R., Murphy, R. J., Ades, H. W.: A comparison of the permanent deleterious effects of noise on the chinchilla resulting from either continuous or intermittent noise. In: Effects of noise on hearing (Henderson, D., Hamernik, R. P., Dosanjh, D. S., Mills, J. H., Eds.), pp. 327-340. New York: Raven Press 1976

Hawkins, J. E. Jr., Johnsson, L.-G.: Microdissection and surface preparations of the inner ear. In: Handbook of auditory and vestibular research methods (Smith, C. A., Vernon, J. A., Eds.), pp. 5-52. Springfield, Ill.: Thomas 1976

Hawkins, J. E. Jr., Johnsson, L.-G., Stebbins, W. C., Moody, D. B., Coombs, S. L.: Hearing loss and cochlear pathology in monkeys after noise exposure. Acta Otolaryngol. 81, 337-343 (1976) 
Hunter-Duvar, I., Elliott, D. N.: Effects of intense auditory stimulation: hearing losses and inner ear changes in the squirrel monkey. J. Acoust. Soc. Amer. 52, 1181-1192 (1972)

Johnsson, L.-G., Hawkins, J. E., Jr.: Degeneration patterns in human ears exposed to noise. Ann. Otol. (St. Louis) 85, 725-739 (1976)

Melnick, W.: Human asymptotic threshold shift. In: Effects of noise on hearing (Henderson, D., Hamernik, R. P., Dosanjh, D. S., Mills, J. H., Eds.), pp. 277-290. New York: Raven Press 1976

Melnick, W., Maves, M.: Asymptotic threshold shift (ATS) in man from 24-hour exposure to continuous noise. Ann. Otol. (St. Louis) 83, 820-828 (1974)

Miller, J. D., Watson, C. S., Covell, W. P.: Deafening effects of noise on the cat. Acta Otolaryngol., Suppl. 176, 1-91 (1963)

Mills, J. H.: Threshold shifts produced by 90-day exposures to noise. In: Effects of noise on hearing (Henderson, D., Hamernik, R. P., Dosanjh, D. S., Mills, J. H., Eds.), pp. 265-276. New York: Raven Press 1976

Moody, D. B., Beecher, M. D., Stebbins, W. C.: Behavioral methods in auditory research. In: Handbook of auditory and vestibular research methods (Smith, C. A., Vernon, J. A., Eds.), pp. 439-495. Springfield, Ill.: Thomas 1976

Moody, D. B., Stebbins, W. C., Miller, J. M.: A primate restraint and handling system for auditory research. Behav. Res. Methods Instrum. 2, 180-182 (1970)

Stebbins, W. C., Miller, J. M., Johnsson, L.-G., Hawkins, J. E., Jr.: Ototoxic hearing loss and cochlear pathology in the monkey. Ann. Otol. (St. Louis) 78, 1007-1025 (1969)

Ward, W. D.: Acoustic trauma and noise-induced hearing loss. In: Human communication and its disorders, Vol. 3 (Tower, D. B., Ed.), pp. 221-229. New York: Raven Press 1976

Ward, W. D., Duvall, A. J.: Behavioral and ultrastructural correlates of acoustic trauma. Ann. Otol. (St. Louis) 80, 881-896 (1971)

Wever, E. G.: The problem of the tonal dip. Laryngoscope 52, 169-187 (1942)

Received October 25, 1977 